\title{
Initiatives and Challenges of Using Gamification in Software Engineering: A Systematic Mapping
}

\author{
Daniel de Paula Porto ${ }^{\mathrm{a}, *}$, Gabriela Martins de Jesus ${ }^{\mathrm{a}}$, Fabiano Cutigi Ferrari ${ }^{\mathrm{a}}$, Sandra \\ Camargo Pinto Ferraz Fabbri ${ }^{a}$ \\ ${ }^{a}$ Computing Department - Federal University of São Carlos - Brazil
}

\begin{abstract}
Context: Gamification is an emerging subject that has been applied in different areas, bringing contributions to different types of activities. Objective: This paper aims to characterize how gamification has been adopted in non-educational contexts of software engineering (SE) activities. Method: We performed a Systematic Mapping of the literature obtained from relevant databases of the area. The searches retrieved 2640 studies (published up to January 2020), of which 548 were duplicates, 82 were selected after applying the inclusion and exclusion criteria, and 21 were included via the backward snowballing technique, thus reaching a total of 103 studies to be analyzed. Results: Gamification provided benefits to activities like requirements specification, development, testing, project management, and support process. There is evidence of gamified support to some CMMI 2.0 Practice Areas. The most commonly used gamification elements are points and leaderboards. The main benefit achieved is the increased engagement and motivation to perform tasks. Conclusion: The number of publications and new research initiatives have increased over the years and, from the original authors' reports, many positive results were achieved in SE activities. Despite this, gamification can still be explored for many SE tasks; for the addressed ones, empirical evidence is very limited.
\end{abstract}

Keywords: Gamification, Software Engineering, Systematic Literature Mapping

\section{Introduction}

Over the years, several advances in the Software Engineering (SE) area have led to the production of new technologies, models and techniques that, in turn, would help to mitigate the challenge of developing high quality software. Despite the progress made to date, the challenge still remains. According to The Standish Group [1], only 36\% of projects conform to the planned time, budget and scope. This represents the same situation observed almost

\footnotetext{
*Corresponding author.

Email addresses: daniel.porto@ufscar.br (Daniel de Paula Porto), gabriela.jesus@ufscar.br (Gabriela Martins de Jesus), fcferrari@ufscar.br (Fabiano Cutigi Ferrari), sfabbri@ufscar.br (Sandra Camargo Pinto Ferraz Fabbri)
} 
20 years ago. This occurs not only due to the lack of research in the subject, but also because of human factors present throughout the development. Consequently, motivation and discipline have become even more crucial elements for good software development [2]. One manner to introduce and keep these two key elements in the considered activities sometimes tedious and not challenging - is the use of gamification.

Gamification is understood as the use of game elements in non-game contexts [3]. It has emerged as a phenomenon and is increasingly present in people's everyday lives [3]. Gamification makes use of game elements and mechanics to stimulate behavior, improve people's motivation and engagement in their tasks [3, 4].

The earliest applications of gamification were in digital marketing strategies to increase customer engagement [3]. Due to its effectiveness, gamification has been spread to other domains, such as education, health, and sales. There are several initiatives of application of gamification in the educational context [5, 6, 7, 8, 9]. Muntean [9], for example, observed that the use of gamification motivates students to study, makes them more interested, and stimulates their learning process.

Recently, the use of gamification has been extended to work environment in order to engage people in their tasks [10]. Hamari et al. [11] mentioned the use of gamification in the following contexts (in addition to the educational one): market, health/fitness, internal system of organizations, sharing, sustainable consumption, work, innovations, and data collection.

Whereas gamification has been applied to several contexts, it has also been explored in SE, thus bringing joy aspects to this context. Beecham et al. [12] stated that one of the biggest challenges for software development companies is to keep teams motivated. Dubois and Tamburrelli [2] argued that the use of gamification in software development has several advantages due to factors like reward mechanisms. Thus, unpleasant tasks for the development team, such as writing unit testing and easy-to-do maintenance, are stimulated with rewards and joy obtained with gamification.

In particular, the application of gamification in SE activities seems to be promising, since over the years several pieces of research have emerged with this purpose [4, 2, 13]. According to García et al. 4], besides improving team motivation and engagement in their activities, it is expected that the use of gamification in SE tasks improves the achieved results, both in terms of product quality and project performance. Moreover, the use of gamification in SE context goes beyond motivation and involvement. There are recent pieces of work that enumerated several benefits of using gamification in the software development environment, such as: encouraging good programming practice [14], identification and fault removal [15], and improvement at performing processes [16].

In the SE field, therefore, researchers and practitioners are aware of the potential benefits of gamification in the workplace. Gamification enables organizations to reward their developers for every aspect of their activities, each completed task, and each written unit test. The mechanics of gamification not only represent a way to reward the team members, but also make the work funnier [4].

As a consequence of those promising applications in the industry, researchers have begun to investigate gamification from some points of view. Even though the gamification subject 
is quite recent and has shown preliminary results, there are already several primary studies regarding that. Moreover, there are some secondary studies that attempt to group these primary studies based either on specific [13, 17, 18, 19, 20, 21, 22, 23, 24, 25, 26, 27] or on general SE perspectives [28, 29, 30].

In order to provide the reader with an up-to-date, comprehensive overview of findings from the use of gamification in non-educational contexts of SE activities, this article reports on the results of a systematic literature mapping. The growing number of publications on this topic may signal awareness of the area about the contribution of gamification to the success of software development projects. More specifically, this article presents and discusses:

- a mapping study that focuses on gamification in non-educational contexts of software engineering;

- the benefits that have already been achieved with gamification;

- which gamification elements have been used, and in which contexts and activities;

- which CMMI 2.0 Practice Areas have been, directly or indirectly, impacted by gamification;

- which tools have been used to date; and

- the challenges and difficulties to implement gamification in the SE context.

It is worth mentioning that in this work we used CMMI as a reference model because it is largely used by the software development industry. According to the CMMI Adoption Trends Report - 2018 Year-End Update [31], approximately $57 \%$ of professionals who train in CMMI are from the software development area. In this same report, it is possible to follow the annual growth in the number of CMMI certifications. Other models were not considered in our study, but they can be mapped to CMMI; examples of such models are ISO 9000 [32]; ISO 12207 [32]; ISO 15288 [32]; ISO 15504 [33]. CMMI can also work in conjunction with Scrum 34 .

Besides this introductory section, the remainder of this article is structured as follows: Section 2 reports on the systematic literature mapping carried out, focusing on gamification elements, activities supported by gamification, achieved benefits, CMMI 2.0 Practice Areas impacted by gamification, used tools, and challenges and difficulties to implement gamification. The systematic mapping results are summarized and discussed in Section 3. A summary of the main findings and implications of this study is presented in Section 4. Section 5 addresses threats to validity, and, Section 6 summarizes the main secondary studies related to this. Finally, Section 7 brings the final considerations and planned future work. 


\section{Mapping Process}

Systematic mappings (SM) provide an overview of the area to be studied and help on the identification of research opportunities. In this section, we describe the SM reported on this article.1 The process adopted was the one proposed by Petersen et al. [35, 36], which is composed of the following activities: definition of the research questions, conduction of the searches and screening of the studies, classification scheme and data extraction, and results mapping. Each of these activities is described in the sequence.

\subsection{Research Questions}

As previously mentioned, this SM is motivated by the need for an up-to-date view of the current uses of gamification in the software engineering context. Our main goal is to understand how gamification has been applied to software engineering. We aim at presenting an overview of where and how gamification elements have been used in a software development life cycle. This overview includes characterizing which and how gamification elements have been mostly used, in which contexts they have been applied, which benefits have been achieved, which CMMI 2.0 Practice Areas have been impacted by gamification, which tools have been used, and which are the challenges and difficulties to implement gamification.

The goal established for this study has two interest dimensions. The first one concerns the gamification elements themselves, with the aim of identifying the ones that have been mostly used and their purpose. The second dimension refers to the activities performed in software engineering, with the aim of identifying and characterizing in which activities gamification has been used. To better guide the study, the main goal of this SLR was mapped into four research questions of more specific contexts, as follows:

RQ1. How is gamification inserted into software engineering activities? This research question aims to identify which gamification elements have been mostly used, and in which software engineering activities they have shown to be useful.

RQ2. How do software engineering activities benefit from gamification? This research question aims to list all direct and indirect benefits achieved through gamification, and identify in which software engineering activities these benefits occur. To better answer this research question, the following sub-question was created: RQ2.1. Which CMMI 2.0 Practice Areas have been impacted by gamification? This sub-question aims to identify which Practice Areas from CMMI 2.0 process model have been, direct or indirectely, impacted by gamification. Here, we tried to relate all the gamification implementation initiatives with the Practice Areas of CMMI 2.0.

RQ3. Which software has supported the gamification implementation and in which contexts it has been used? This research question aims to identify the software systems that have been used to implement gamification and in what contexts they have been used.

RQ4. What are the challenges and difficulties of deploying gamification in software engineering? Finally, this research question aims to identify which are the

\footnotetext{
${ }^{1}$ The complete protocol of this SM can be accessed in https://goo.gl/pQHYV7
} 
difficulties and challenges of implementing gamification in software engineering, as reported in the literature.

\subsection{Conducting Search and Screening of Papers}

\subsubsection{Search String}

In order to construct the search string, we selected the main terms and synonyms found in previously known studies, following the recommendation of Kitchenham and Charters [37. At this point, the relevant keywords found in known secondary studies were also used. After some initial tests, we decided to complement the string with other synonyms, so that its range was as large as possible. The final search string can be seen in Figure 1 .

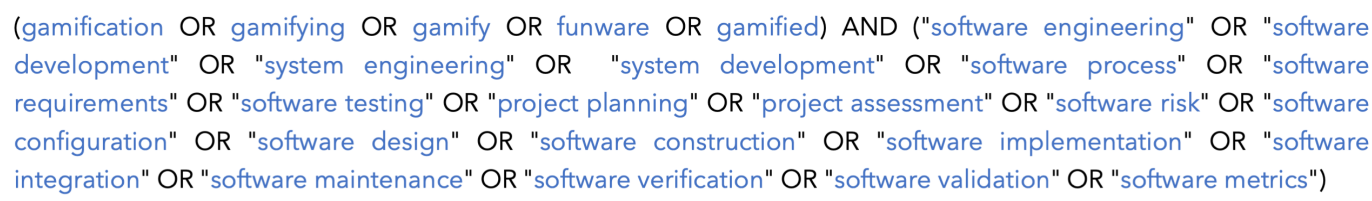

Figure 1: Used search string.

We did not define a time frame to narrow search results, given that as far as the use of gamification elements in software engineering context has began recently, any restriction in this way could disregard relevant publications to our research. To check the search string consistency, a control group was created containing some relevant and previously known articles. Results that were retrieved with the search string included all studies from the control group.

\subsubsection{Inclusion and Exclusion Criteria}

To avoid subjectivity in study selection and focus only on gamification in the software engineering context, we defined the inclusion (i) and exclusion criteria (e) listed in the sequence. Note that a study was selected if it passed i1 and did not pass in any of the exclusion criteria.

i1. Addresses the use of gamification in the software engineering context;

e1. Considers gamification in the educational or training context;

e2. Does not consider gamification in software engineering;

e3. Is not an end software engineering activity;

e4. Is an index or preface of another publication;

e5. Is not written in English;

e6. Addresses real games or serious games;

e7. Is a secondary study. 
e8. Is not available online.

Regarding the exclusion criteria, concerning criteria e1, in our research, we classified as educational or training context any study in which the applicability of the proposal occurs exclusively in these contexts. Even though training is an activity present in software development, it is only a secondary activity in the development process (excluded by criterion e3). Besides that, if training-related studies were selected, all studies in the educational context should also be selected as these could be used as training in a real company. To select all educational studies, the search string should be different and would bring a large number of other studies. Regarding the e4 criterion, it is important to mention that many search engines return, in addition to studies, conference indexes, or prefaces. Therefore, e4 was created to exclude these results from the search.

\subsubsection{Search process}

After the definition of the search string and the inclusion and exclusion criteria, the next step was to identify the primary studies. Two searches were carried out. The first (Search 1) was performed on July, 2018, in five databases (details next, in this section) that index studies published in proceedings of scientific events, in journals, or books, all related to the subject. A second search (Search 2) was run in January, 2020, with the intent of making our results up-to-date; for this, we used the same search string and the same databases.

Searches have targeted title, abstract, and keywords of studies. Figure 2 illustrates the performed process. For Search 1, the Figure 2 shows that 1504 studies were retrieved as a result of the application of the search string in all databases. From these studies, the duplicates were removed (Filter 1), reducing the list to 1282 studies. The application of inclusion and exclusion criteria (Filter 2) reduced the list to 56 studies. Based on these 56 studies and also in the studies discarded by criteria e7 (secondary studies), we applied an iteration of the backward snowballing technique [38. The purpose of backward snowballing is to use the reference list of selected studies to identify new studies to be included. The first step is to list all possible new primary studies from the list of references of the selected papers. Afterwards, such studies go through the same selection steps carried out for the studies retrieved with automatic search (i.e. Filters 1 and 2 are applied). In total, 1964 additional items were retrieved. From these, 657 duplicates were removed (Filter 1), decreasing the number of entries to 1307 studies. Then, inclusion and exclusion criteria were applied (Filter 2), which reduced the list to 10 studies. The final list from Search 1 was composed by 56 studies found early and the 10 recovered by snowballing.

For the second search (Search 2), we performed exactly the same steps as performed for Search 1, and ended up with a final list of 37 studies. The final list of selected studies includes the 66 selected studies from Search 1, as well as the 37 selected studies on Search 2, thus composing a set of 103 studies. Note that, hereafter, we refer to the primary studies selected in this SM by using the naming convention $\mathrm{S}<\mathrm{NUMBER}>$, where $<$ NUMBER $>$ is a sequential number. The complete list of selected studies can be found in Appendix B.

The surveyed search engines were: (i) ACM Digital Library (DL) ${ }^{2}$ (ii) IEEE Xplore

\footnotetext{
2 http://dl.acm.org - accessed on 13-September-2020
} 


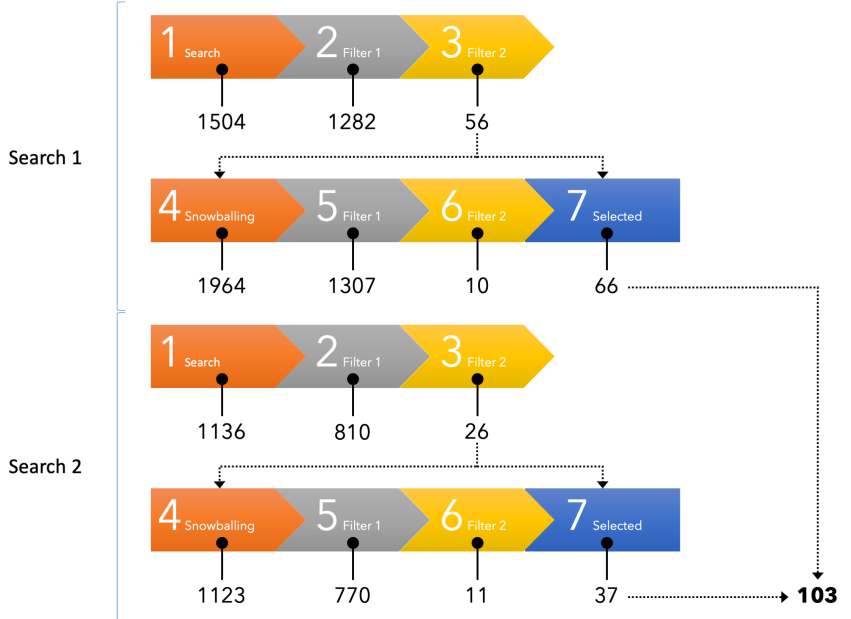

Figure 2: Search process.

Digital Library: $:^{3}$ (iii) Elsevier ScienceDirect:44(iv) Elsevier Scopus: $:^{5}$ and (v) Springer Nature SpringerLink ${ }^{6}$ Table 1 shows the number of studies at the end of each phase, by type of search. The search engine that retrieved more studies was SpringerLink, finding more than three times studies than Scopus. However, after the application of filters 1 and 2, we verified that Scopus was the most effective, contributing with 65 selected studies, while SpringerLink contributed with only six. It is noteworthy the importance of the snowballing technique, which led to the inclusion of the second largest number of studies (21, in total). Furthermore, due to the "hybrid" nature of some search engines (e.g. Scopus' and ACM's search results overlap results from other queried databases), in Table 2 we provide more precise information regarding the number of studies selected per publisher. Table 2 shows that the publisher with the largest number of selected studies is IEEE with 30 studies, followed by Springer with 23 and ACM with 17. All other publishers contributed at most with 4 studies each.

Table 1: Studies by search type at the end of each phase.

\begin{tabular}{lccc}
\hline Search & $\begin{array}{c}\text { Found } \\
\text { studies }\end{array}$ & $\begin{array}{c}\text { Studies after } \\
\text { filter 1 }\end{array}$ & $\begin{array}{c}\text { Studies after } \\
\text { filter 2 }\end{array}$ \\
\hline String - ACM & 228 & 160 & 3 \\
String - IEEE & 174 & 72 & 7 \\
String - ScienceDirect & 32 & 1 & 1 \\
String - Scopus & 541 & 470 & 65 \\
String - Springer & 1665 & 1390 & 6 \\
Snowballing & 3087 & 2077 & 21 \\
\hline Total & 5727 & 4170 & 103
\end{tabular}

Table 1 shows that Filter 1 restricted the number of studies in more than $25 \%$ of the total found (1557 of 5727). It should be noted that filter 1 was performed automatically using the

\footnotetext{
3 http://www. ieeexplore.ieee.org - accessed on 13-September-2020

4 http://www.sciencedirect.com - accessed on 13-September-2020

5 http://www.scopus.com - accessed on 13-September-2020

6 https://link.springer.com - accessed on 13-September-2020
} 
Table 2: Studies by publisher.

\begin{tabular}{ll}
\hline Publisher & $\#$ \\
\hline IEEE & 30 \\
Springer & 23 \\
ACM & 17 \\
Others & 33 \\
\hline
\end{tabular}

StArt tool [39], which greatly reduced working time and chances of errors (in comparison with manual work). Table 1 also shows that Filter 2 (inclusion and exclusion criteria) was responsible for restricting more than $97 \%$ of the non-duplicates (4067 out of 4170), reducing the final number of studies selected to almost $2 \%$ of the total originally retrieved (103 out of 5727). Table 3 shows the reasons that led the studies to be discarded by Filter 2. Note that exclusion criteria e1 and e2 were responsible for discarding almost 90\% studies (3626 out of 4067).

Table 3: Number of studies discarded by exclusion criteria.

\begin{tabular}{lc}
\hline Exclusion criteria & Discarded studies \\
\hline e1. Considers gamification in the educational or training context & 816 \\
e2. Does not consider gamification in software engineering & 2810 \\
e3. It is not an end software engineering activity & 58 \\
e4. Is an index or preface of another publication & 127 \\
e5. Is not written in English & 68 \\
e6. Addresses real games or serious games & 87 \\
e7. Is a secondary study & 100 \\
e8. Is not available online & 1 \\
\hline Total & 4067 \\
\hline
\end{tabular}

The selection of primary studies was performed by one author, according to the inclusion and exclusion criteria. All conflicts in the study selection were resolved with support of additional authors in order to reduce potential threats. After applying filters, and based on the questions to be answered, the data to be collected from the studies was established to support the systematic mapping synthesis. This is presented next.

\subsection{Classification Scheme and Data Extraction}

We established seven data extraction steps (and associated data fields): (i) retrieve study metadata; (ii) analyze which gamification elements have been used; (iii) identify the software engineering activities benefited from gamification; (iv) analyze gamification benefits presented in the studies; (v) analyze the relationship between gamified activities and CMMI 2.0 Practice Areas; (vi) identify used tools; and (vii) identify challenges and difficulties for implementing gamification. In order to answer the research questions listed in Section 2.1, the following data fields and classification scheme were adopted:

Studies metadata: Publication venue, publication type, year of publication, type of study, research method, and country of author affiliation. Regarding the types of publications, the studies were categorized as Conferences Papers, Articles, Books, Book Chapters, Master's Dissertation, and $\mathrm{PhD}$ Thesis. Concerning the type of study, in relation to the addressed content, we classified the selected studies in the six categories proposed by Wieringa et al. 
[40]: Validation Research, Evaluation Research, Proposal of Solution, Philosophical Papers, Opinion Papers, and Personal experience paper. Regarding the research method, we used the classification suggested by Petersen et al. [36]: Case Study, Experiment, and Survey. The option No experimental study has been carried out was added to this list.

Gamification elements (RQ1): The taxonomy for gamification elements was based on a book of Werbach and Hunter [41]; The elements taken from the study are: avatar, social graphs, betting7] leaderboards, voting ${ }^{7}$, challenges, levels, badges, points, and rewards.

Software engineering activities (RQ1, RQ2): The software engineering activities were also extracted from a secondary study by other authors [29]. The selected software engineering activities (derived from ISO/IEC 12207 standard) are: Project Management, Requirements, Development, Testing, and Support Processes.

Benefits achieved with gamification (RQ2): The studies were analyzed according to direct and indirect benefits achieved with gamification.

$C M M I$ 2.0 Practice Areas (RQ2.1): The studies were analyzed in relation to activities supported by gamification to compare them with the activities mentioned in the software maturity models. For this relationship, we used the Practice Areas of the CMMI 2.0 model as a reference. The Practice Areas in the model are: Requirements development and management (RDM), Process quality assurance (PQA), Verification and validation (VV), Peer reviews (PR), Technical solution (TS), Product integration (PI), Supplier agreement management (SAM), Estimating (EST), Planning (PLAN), Monitor and control (MC), Risk and opportunity management (RSK), Organizational training (OT), Causal analysis and resolution (CAR), Decision analysis and resolution (DAR), Configuration management (CM), Governance (GOV), Implementation infrastructure (II), Process management (PCM), Process asset development (PAD), and Managing performance and measurement (MPM).

Used tools (RQ3): The studies were analyzed in relation to supporting tools, distinguishing whether they described any tool that supports gamification or not. In addition, we identified which tools were presented, in which contexts they were used, and the kind of support. The kind of support can be gamified tools (tools with gamification ready to use) or tools enabling gamification (tools that make it possible to create a gamified environment).

Challenges and difficulties regarding gamification (RQ4): The studies were analyzed according to the difficulties and challenges brought about by the gamification deployment.

We used a data extraction form designed to gather the aforementioned data. As in the step of study selection, one author has read each study, applied the classification scheme, and performed the data extraction. When the decision for including a study was not clear, other authors were involved in the decision making process. The data extraction step was also performed using the StArt tool [39], which supports the MS process and reduces its execution time. The extracted data was analyzed in order to answer all questions presented in section 2.1. A synthesis of the achieved results is presented in the next section.

\footnotetext{
${ }^{7}$ The betting and voting elements do not appear in the Werbach and Hunter [41]'s taxonomy. Therefore, they were added to the list due to the fact that they explicitly appear in the selected studies.
} 


\section{Results}

This section presents the main results of this systematic mapping. A discussion is presented in order to answer the research questions set out in Section 2.1.

\subsection{Analysis of Study Metadata}

We identified 65 different publication venues. 8 Figure 3 highlights the 16 venues with two or more selected studies. This group represents almost 40\% (41 of 103) of the selected studies. The venue with the largest number of selected studies (9, in total) was the EuroSPI conference (European Conference on Software Process Improvement).

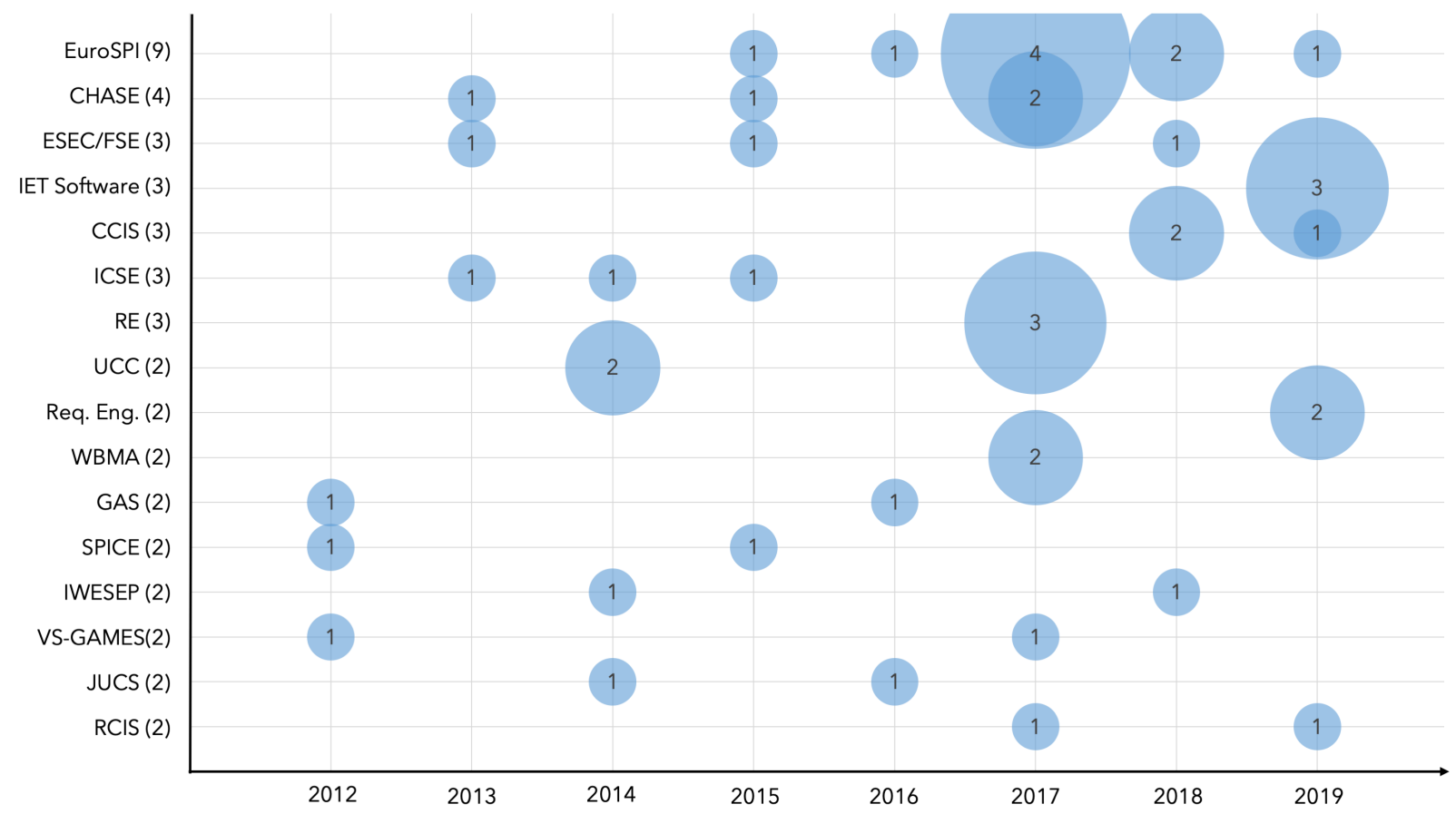

Figure 3: Main publication venues by year.

Regarding the types of publications, Table 4 shows that the vast majority of studies (93) are papers or articles. In total, 76 studies were published in conferences proceedings, and 17 studies were published in journals. In addition to the papers and articles, we also selected 7 Master's dissertation, 1 book, 1 book chapter, and 1 PhD Thesis.

The distribution of selected studies along the years reveals the evolution of gamification adoption. This is depicted in Figure 4. In 2011 Deterding et al. 3 stated that gamification was an emerging issue. Figure 4 shows a gradual increase in the number of studies retrieved up to 2018. In 2019 there is a small drop (note that numbers for 2020 are only partial). Perhaps the subject of gamification in software engineering peaked in 2018 and its popularity

\footnotetext{
${ }^{8}$ All publication venues can be accessed in https://bit.1y/353LWge
} 
Table 4: Publication types.

\begin{tabular}{lc}
\hline Publication type & Number \\
\hline Conference Paper & 76 \\
Article & 17 \\
MSc. Dissertation & 7 \\
PhD. Thesis & 1 \\
Book & 1 \\
Book Chapter & 1 \\
\hline
\end{tabular}

has reached a plateau ever since, though we may need some additional years to draw definite conclusions on it. It is important to remember that the retrieved studies were filtered (according to the search string). Given the large number of gamification studies related to other contexts, it is likely that Figure 4 would be different if the search string was directed to gamification in general. Another possibility is that Deterding et al. [3]'s claim is no longer valid almost a decade later.

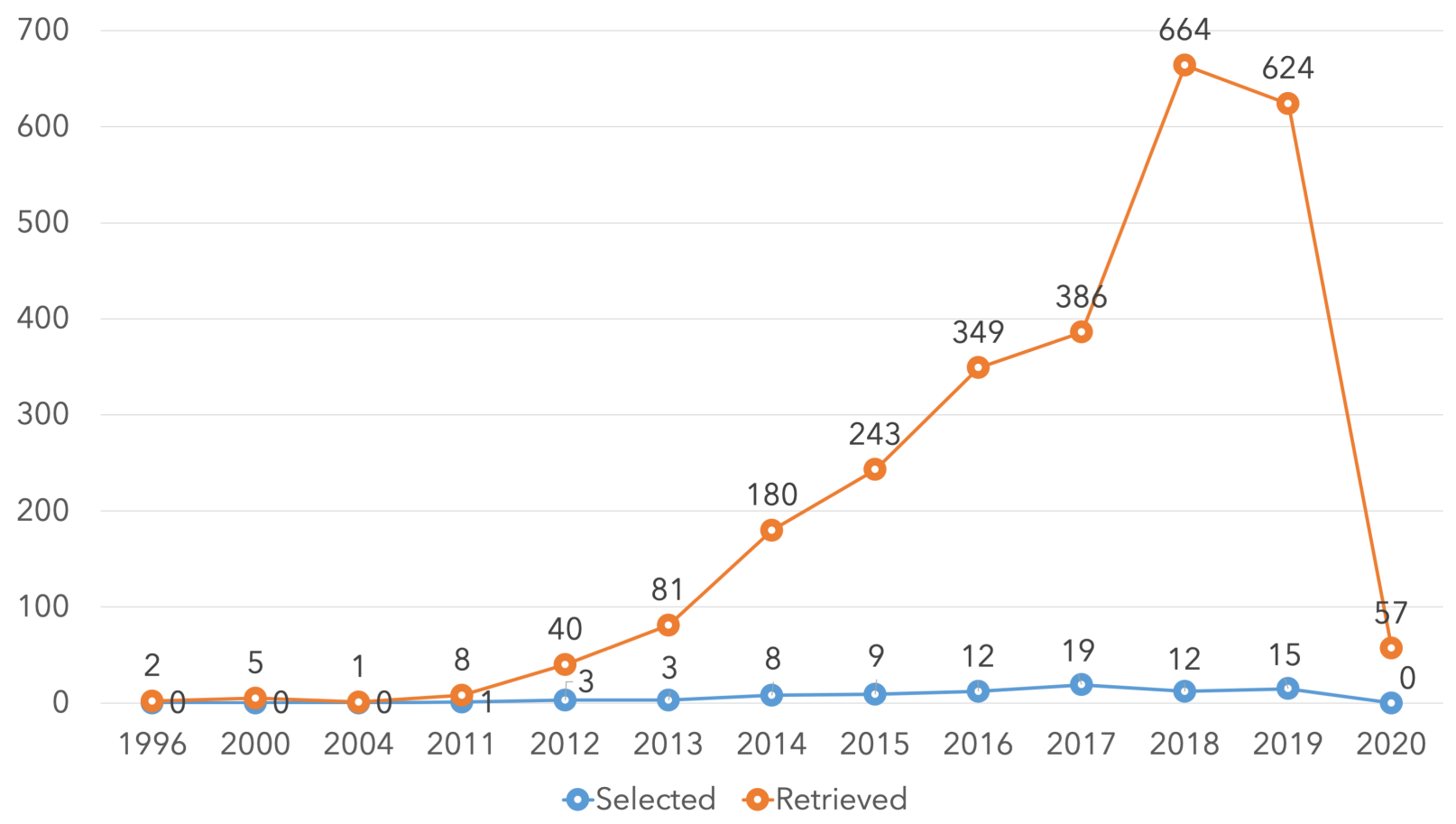

Figure 4: Number of publications per year.

Information about the type of study can be seen in Table 5. By focusing on the numbers of studies classified as Proposal of Solution and Validation Research in Table 5, we notice that both encompass $83 \%$ of the selected studies. These two categories represent studies at an earlier stage, for which there is no robust statistical analysis of the experiment carried out. This may reflect the short time of use of gamification and the immaturity of several studies.

Regarding the research method, Table 6 shows that many studies (32, in total) did not present any experimental evaluation. This reinforces the large number of studies in the early 
Table 5: Selected studies type.

\begin{tabular}{|c|c|c|}
\hline Studies type & Number & Studies \\
\hline Evaluation Research & 14 & {$[\mathrm{~S} 2],[\mathrm{S} 10],[\mathrm{S} 14],[\mathrm{S} 16],[\mathrm{S} 21],[\mathrm{S} 26],[\mathrm{S} 46],[\mathrm{S} 61],[\mathrm{S} 69],[\mathrm{S} 70],[\mathrm{S} 75],[\mathrm{S} 78],[\mathrm{S} 81],[\mathrm{S} 90]$} \\
\hline Proposal of Solution & 40 & $\begin{array}{l}\text { [S7], [S8], [S9], [S12], [S13], [S20], [S23], [S24], [S25], [S27], [S28], [S29], [S33], [S34], [S38], } \\
\text { [S44], [S45], [S50], [S52], [S57], [S58], [S59], [S64], [S65], [S72], [S74], [S76], [S79], [S85], } \\
\text { [S87], [S89], [S91], [S92], [S93], [S94], [S96], [S98], [S100], [S102], [S103] }\end{array}$ \\
\hline Validation Research & 46 & $\begin{array}{l}\text { [S1], [S3], [S4], [S5], [S6], [S11], [S15], [S17], [S18], [S19], [S22], [S30], [S31], [S32], [S35], } \\
\text { [S36], [S37], [S39], [S40], [S41], [S42], [S43], [S47], [S48], [S49], [S51], [S53], [S54], [S56], } \\
\text { [S60], [S62], [S63], [S66], [S67], [S68], [S71], [S73], [S77], [S80], [S82], [S83], [S86], [S88], } \\
\text { [S95], [S99], [S101] }\end{array}$ \\
\hline Philosophical Papers & 1 & {$[\mathrm{~S} 55]$} \\
\hline Opinion Papers & 2 & [S84], [S97] \\
\hline
\end{tabular}

stages shown in Table 5. From the studies that presented experimental evaluation, 30 presented a case study, whereas 22 presented controlled experiments, and only 19 presented surveys.

Table 6: Research Methods.

\begin{tabular}{|c|c|c|}
\hline Research Method & Number & Studies \\
\hline Case Study & 30 & $\begin{array}{l}\text { [S2], [S5], [S10], [S15], [S22], [S26], [S27], [S32], [S36], [S37], [S39], [S47], [S48], [S54], } \\
\text { [S60], [S61], [S68], [S69], [S71], [S73], [S75], [S81], [S82], [S83], [S86], [S90], [S95], } \\
\text { [S97], [S98], [S103] }\end{array}$ \\
\hline Experiment & 22 & $\begin{array}{l}\text { [S1], [S6], [S11], [S16], [S17], [S18], [S21], [S30], [S31], [S42], [S43], [S51], [S53], [S62], } \\
{[\mathrm{S} 63],[\mathrm{S} 66],[\mathrm{S} 67],[\mathrm{S} 74],[\mathrm{S} 78],[\mathrm{S} 80],[\mathrm{S} 88],[\mathrm{S} 99]}\end{array}$ \\
\hline Survey & 19 & $\begin{array}{l}\text { [S3], [S9], [S14], [S28], [S35], [S40], [S41], [S45], [S46], [S49], [S50], [S52], [S55], [S59], } \\
{[\mathrm{S} 70],[\mathrm{S} 76],[\mathrm{S} 79],[\mathrm{S} 92],[\mathrm{S} 100]}\end{array}$ \\
\hline $\begin{array}{l}\text { No experimental study } \\
\text { has been carried out }\end{array}$ & 32 & $\begin{array}{l}\text { [S4], [S7], [S8], [S12], [S13], [S19], [S20], [S23], [S24], [S25], [S29], [S33], [S34], [S38], } \\
\left.\text { [S44], [S56], [S57], [S58], [S64], [S65], [S72], [S77], [S84], [S85], [S87], [S89], }{ }^{\mathrm{S}} 91\right] \text {, } \\
\text { [S93], [S94], [S96], [S101], [S102] }\end{array}$ \\
\hline
\end{tabular}

Regarding the coutries of authors' affiliation, Table 7 shows that, among the selected studies, Spain and Brazil are the countries with the largest number of published studies (10), followed by United States (9), and Switzerland, India and Italy (8).

Table 7: Author's affiliation countries.

\begin{tabular}{lclc}
\hline Country & Number & Country & Number \\
\hline Spain & 10 & Sweden & 4 \\
Brazil & 10 & Japan & 4 \\
United States & 9 & Ireland & 4 \\
Switzerland & 8 & Turkey & 4 \\
India & 8 & France & 3 \\
Italy & 8 & Austria & 2 \\
Germany & 7 & Colombia & 2 \\
United Kingdom & 7 & Australia & 1 \\
Portugal & 6 & Belgium & 1 \\
Netherlands & 6 & Saudi Arabia & 1 \\
Mexico & 6 & Chile & 1 \\
Canada & 6 & Lithuania & 1 \\
Norway & 5 & China & 1 \\
Israel & 5 & Malaysia & 1 \\
\hline
\end{tabular}

We next analyze the results with respect to the research questions established for this 
study.

\section{2. (RQ1) How is gamification inserted into software engineering activities?}

In order to answer this research question, it is necessary to analyze the selected studies from two perspectives: the use of gamification elements, and the activities supported by them. Regarding the first perspective, Table 8 shows the occurrence of each gamification element and the respective selected studies that quote them. It is worth remembering that the occurrences are counted from explicit quotations within the studies.

Table 8: Occurrence of gamification elements in selected studies.

\begin{tabular}{|c|c|c|}
\hline Gamification element & Number & Studies \\
\hline Points & 87 & 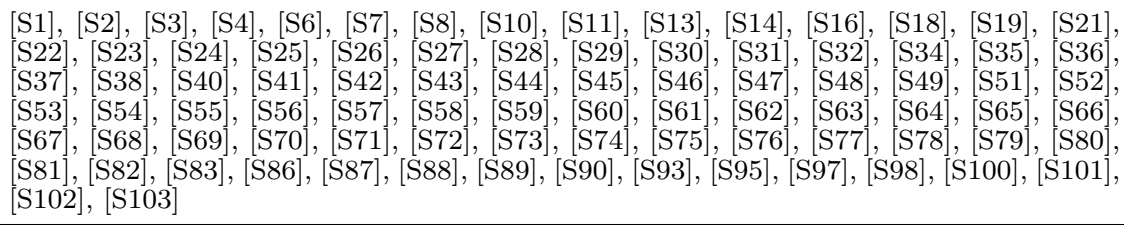 \\
\hline Leaderboards & 62 & 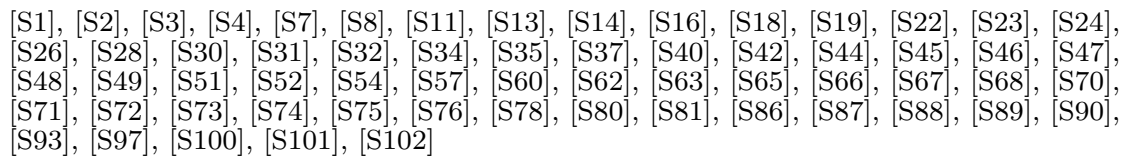 \\
\hline Badges & 49 & $\begin{array}{l}\text { [S2], [S7], [S8], [S11], [S14], [S15], [S19], [S22], [S23], [S25], [S28], [S30], [S31], [S34], } \\
\text { [S37], [S38], [S39], [S40], [S45], [S46], [S47], [S49], [S50], [S51], [S52], [S53], [S55], [S57], } \\
\text { [S59], [S61], [S65], [S66], [S67], [S68], [S69], [S70], [S71], [S77], [S82], [S83], [S87], [S89], } \\
\text { [S90], [S93], [S97], [S98], [S100], [S101], [S103] }\end{array}$ \\
\hline Levels & 34 & $\begin{array}{l}\text { [S2], [S3], [S7], [S10], [S11], [S14], [S19], [S21], [S22], [S31], [S35], [S37], [S38], [S40], } \\
\text { [S47], [S51], [S53], [S56], [S57], [S67], [S68], [S69], [S71], [S77], [S78], [S83], [S86], [S87], } \\
\text { [S89], [S93], [S95], [S98], [S100], [S103] }\end{array}$ \\
\hline Rewards & 33 & $\begin{array}{l}\text { [S1], [S9], [S10], [S11], [S14], [S19], [S22], [S30], [S31], [S34], [S40], [S44], [S45], [S46], } \\
\text { [S47], [S48], [S52], [S57], [S59], [S61], [S64], [S65], [S68], [S69], [S83], [S89], [S90], [S98], } \\
\text { [S99], [S100], [S101], [S102], [S103] }\end{array}$ \\
\hline Challenges & 21 & $\begin{array}{l}{[\mathrm{S} 2],[\mathrm{S} 7],[\mathrm{S} 9],[\mathrm{S} 11],[\mathrm{S} 22],[\mathrm{S} 27],[\mathrm{S} 29],[\mathrm{S} 30],[\mathrm{S} 31],[\mathrm{S} 36],[\mathrm{S} 41],[\mathrm{S} 49],[\mathrm{S} 51],[\mathrm{S} 61],} \\
{[\mathrm{S} 68],[\mathrm{S} 78],[\mathrm{S} 82],[\mathrm{S} 87],[\mathrm{S} 89],[\mathrm{S} 98],[\mathrm{S} 100]}\end{array}$ \\
\hline Social Graphs & 14 & {$[\mathrm{~S} 2],[\mathrm{S} 4],[\mathrm{S} 11],[\mathrm{S} 13],[\mathrm{S} 19],[\mathrm{S} 22],[\mathrm{S} 34],[\mathrm{S} 51],[\mathrm{S} 60],[\mathrm{S} 68],[\mathrm{S} 72],[\mathrm{S} 73],[\mathrm{S} 93],[\mathrm{S} 101]$} \\
\hline Avatar & 14 & {$[\mathrm{~S} 2],[\mathrm{S} 11],[\mathrm{S} 12],[\mathrm{S} 15],[\mathrm{S} 22],[\mathrm{S} 31],[\mathrm{S} 37],[\mathrm{S} 45],[\mathrm{S} 49],[\mathrm{S} 50],[\mathrm{S} 52],[\mathrm{S} 68],[\mathrm{S} 77],[\mathrm{S} 78]$} \\
\hline Voting & 11 & {$[\mathrm{~S} 5],[\mathrm{S} 22],[\mathrm{S} 25],[\mathrm{S} 27],[\mathrm{S} 29],[\mathrm{S} 36],[\mathrm{S} 53],[\mathrm{S} 71],[\mathrm{S} 79],[\mathrm{S} 81],[\mathrm{S} 88]$} \\
\hline Betting & 2 & [S17], [S22] \\
\hline
\end{tabular}

By looking at Table 8, it is notorious that points and leaderboards were the most used elements. As an example, we refer to the study by Prause and Jarke [S42], in which points were given according to code adherence to conventions set forth. In this way, a leaderboard shows the developers who produce code more according to the convention. Another example is the study of Snipes et al. [S35], in which points and leaderboards were used to motivate developers to access certain functionality on IDE, such as viewing method call hierarchies, navigating to variable definitions, and opening class diagrams. On the other hand, voting and betting mechanisms were less explored. These last two mechanisms appeared mainly in requirements and agile process activities, respectively. 
On the second perspective of this research question, Table 9 presents the list of studies that aided each software development activity. It is noted that, nowadays, development activities are the ones that have the most support of gamification. Among several development activities, code review was the most supported by gamification (10 studies). The others activities supported by gamification were: Project Management, Requirements, Testing, and Support Processes. Note that, in some cases, the benefits obtained with gamification were observed by more than one activity and, therefore, the study was mapped to more than one activity.

Table 9: Activities supported by gamification.

\begin{tabular}{|c|c|c|}
\hline Activity & Number & Studies \\
\hline Project Management & 15 & $\begin{array}{l}\text { [S2], [S5], [S7], [S9], [S17], [S33], [S34], [S41], [S44], [S46], [S68], [S97], [S98], [S100], } \\
{[\mathrm{S} 103]}\end{array}$ \\
\hline Requirements & 22 & $\begin{array}{l}\text { [S2], [S14], [S20], [S21], [S25], [S27], [S29], [S31], [S32], [S36], [S47], [S51], [S53], [S54], } \\
{[\mathrm{S} 55],[\mathrm{S} 61],[\mathrm{S} 72],[\mathrm{S} 75],[\mathrm{S} 81],[\mathrm{S} 82],[\mathrm{S} 87],\left[{ }^{\mathrm{S}} 90\right]}\end{array}$ \\
\hline Development & 35 & $\begin{array}{l}\text { [S1], [S3], [S6], [S8], [S11], [S16], [S18], [S19], [S24], [S28], [S34], [S35], [S37], [S38], [S41], } \\
\text { [S42], }[\mathrm{S} 49],[\mathrm{S} 56],[\mathrm{S} 58],[\mathrm{S} 59],[\mathrm{S} 62],[\mathrm{S} 63],[\mathrm{S} 65],[\mathrm{S} 66],[\mathrm{S} 70],[\mathrm{S} 74],[\mathrm{S} 76],[\mathrm{S} 77],[\mathrm{S} 78], \\
\text { [S79], [S85], [S94], [S96], [S99], [S102] }\end{array}$ \\
\hline Testing & 15 & $\begin{array}{l}\text { [S2], [S12], [S15], [S26], [S37], [S50], [S65], [S77], [S78], [S80], [S84], [S86], [S91], [S94], } \\
\text { [S95] }\end{array}$ \\
\hline Support Processes & 27 & $\begin{array}{l}\text { [S4], [S10], [S13], [S22], [S23], [S26], [S30], [S39], [S40], [S43], [S45], [S48], [S52], [S57], } \\
{[\mathrm{S} 60],[\mathrm{S} 64],[\mathrm{S} 67],[\mathrm{S} 69],[\mathrm{S} 71],[\mathrm{S} 73],[\mathrm{S} 83],[\mathrm{S} 89],[\mathrm{S} 91],[\mathrm{S} 92],[\mathrm{S} 93],[\mathrm{S} 101],[\mathrm{S} 103]}\end{array}$ \\
\hline
\end{tabular}

With regard to Project Management activities, the most cited contribution among the studies was the improvement in the people's engagement and motivation to execute the activities (6 studies). Regarding Requirements-related activities, the most explored with gamification was the increase of stakeholder involvement during elicitation of requirements (11 studies). Defect logging and improvement in the people's engagement and motivation to execute the activities, both reported in 5 studies, were the main Testing activities supported by gamification. Finally, for Support Processes, support to agile process was cited in 14 studies as the main benefit obtained through gamification.

Another important piece of information extracted from the studies is the relationship between software development activities and the types of studies. This is depicted in Figure 5. The studies are concentrated in the Proposal of Solution, and Validation Research types. It is also possible to observe a concentration of studies in the development activity. Once again, note that a given study can be related to several activities simultaneously.

Figure 6 presents a chart with the relationship between gamification elements and software engineering activities. It shows how many studies mentioned a particular element as a support for a given activity. It should be noted that the same element may have been reported in more than one study, and one study may have mentioned more than one element.

Figure 6 provides evidence regarding the wide use of points as a gamification element, and as a great support for development activities. On the other hand, it is noted that the betting element has not been much explored, appearing in only two studies to support project management and testing activities. The voting element, on the other hand, has been mainly explored in the Requirements activity, so that people involved could vote on what 


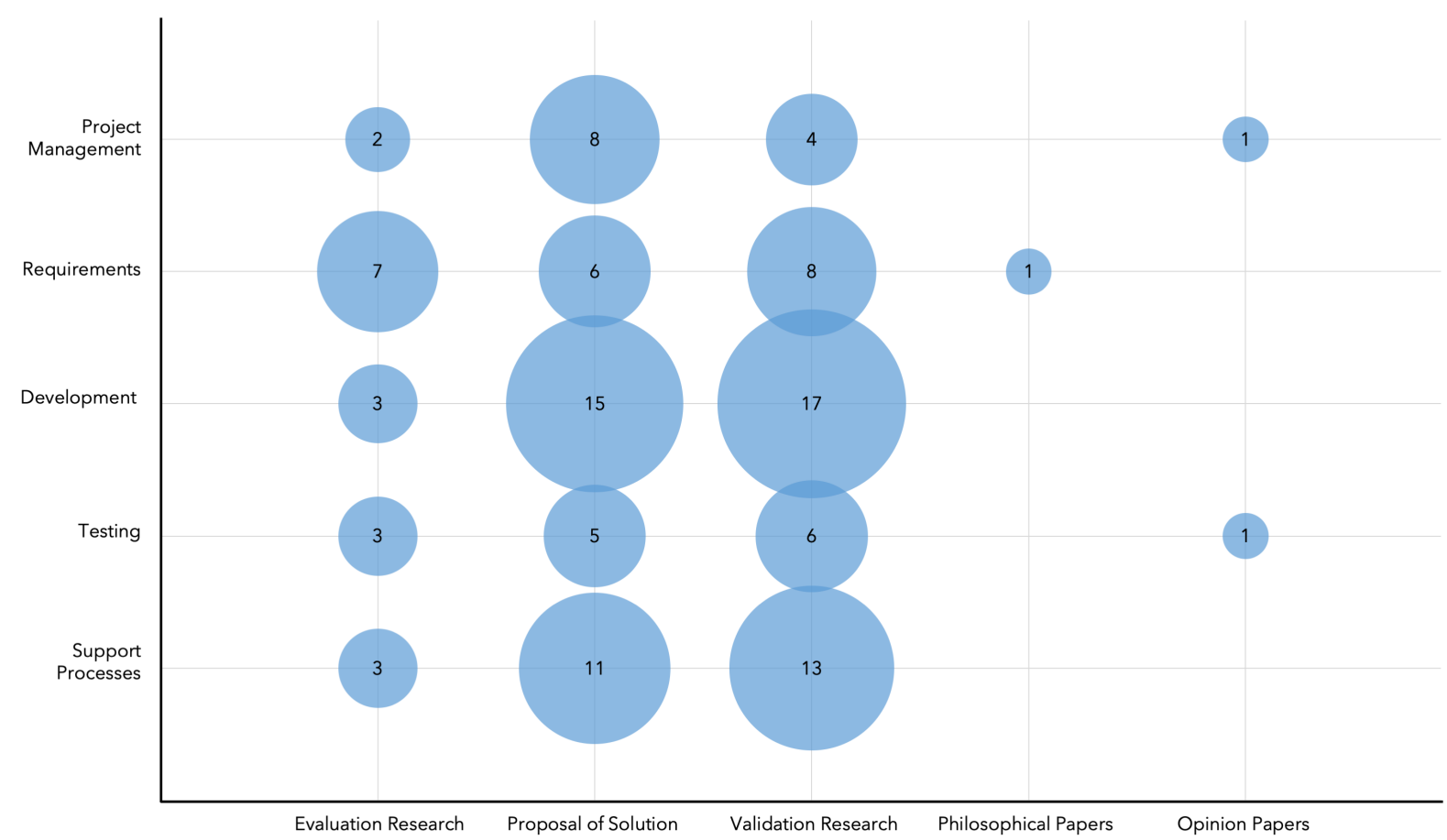

Figure 5: Relationship between study types and software engineering activities.

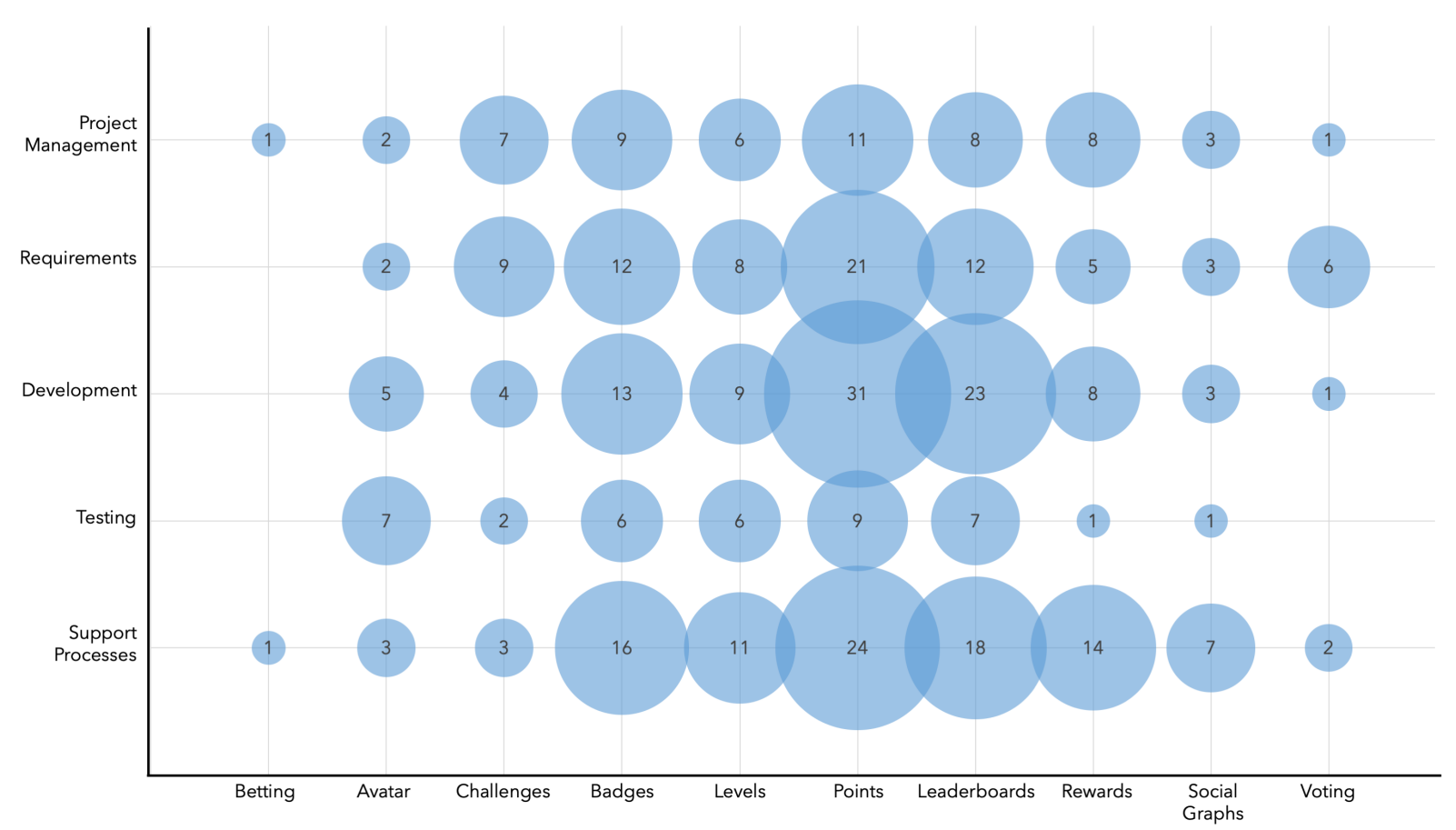

Figure 6: Number of studies that relate gamification elements to software engineering activities. 
requirements they want for the system. Therefore, the Figure 6 brings a broad view of the activities in which gamification elements have been widely or little explored.

Thus, revisiting our research question RQ1, it becomes clear that gamification is mainly inserted in SE activities by adopting the gamification elements mentioned in Figure6. At the same time, the use of gamification in the activities of Project Management, Requirements, Development, Testing, and Support Processes is notorious. It is also noteworthy the little depth of the studies, since they focus on the Proposal of Solution and Validation Research types (Figure 5).

\section{3. (RQ2) How do software engineering activities benefit from gamification?}

In order to answer RQ2, we identified direct and indirect benefits achieved with the use of gamification. This is summarized in Table 10, separated by activities, the benefits obtained with gamification, and the studies in which the benefits were reported.

For the Project Management activity, the main identified benefits were the increase in the engagement and motivation for the team to execute the activities, and also in the improvement of the quality of work performed.

Table 10: Benefits achieved with gamification.

\begin{tabular}{|c|c|c|c|}
\hline Activity & Benefit & Number & Studies \\
\hline $\begin{array}{l}\text { Project } \\
\text { Management }\end{array}$ & $\begin{array}{l}\text { Engage and motivate to perform activities } \\
\text { Improve the quality of work performed } \\
\text { Facilitate activities distribution } \\
\text { Increase team integration }\end{array}$ & $\begin{array}{l}6 \\
4 \\
3 \\
2\end{array}$ & $\begin{array}{l}\text { [S5], [S9], [S41], [S44], [S98], [S103] } \\
{[\mathrm{S} 2],[\mathrm{S} 68],[\mathrm{S} 97],[\mathrm{S} 100]} \\
{[\mathrm{S} 17],[\mathrm{S} 34],[\mathrm{S} 46]} \\
{[\mathrm{S} 7],[\mathrm{S} 33]}\end{array}$ \\
\hline Requirements & $\begin{array}{l}\text { Improve the engagement of stakeholders } \\
\text { Facilitate requirements prioritization } \\
\text { Engage and motivate to perform activities } \\
\text { Improve the quality of work performed }\end{array}$ & $\begin{array}{l}6 \\
3 \\
2\end{array}$ & $\begin{array}{l}\text { [S20], [S31], [S32], [S47], [S51], [S54], [S61], } \\
{[\mathrm{S} 72],[\mathrm{S} 75],[\mathrm{S} 81],[\mathrm{S} 87]} \\
{[\mathrm{S} 21],[\mathrm{S} 27],[\mathrm{S} 29],[\mathrm{S} 36],[\mathrm{S} 53],[\mathrm{S} 90]} \\
{[\mathrm{S} 14],[\mathrm{S} 55],[\mathrm{S} 82]} \\
{[\mathrm{S} 2],[\mathrm{S} 25]}\end{array}$ \\
\hline Development & $\begin{array}{l}\text { Encourage code review } \\
\text { Engage and motivate to perform activities } \\
\text { Encourage good programming practices } \\
\text { Update traceability matrix } \\
\text { Improve software documentation } \\
\text { Improve the quality of work performed } \\
\text { Shorten the coding time } \\
\text { Encourage bug removal } \\
\text { Stimulate code convention adherence } \\
\text { Encourage frequent commit } \\
\text { Encourage code refactoring }\end{array}$ & $\begin{array}{l}3 \\
2 \\
2 \\
2 \\
2 \\
2 \\
1 \\
1 \\
1\end{array}$ & $\begin{array}{l}{[\mathrm{S} 6],[\mathrm{S} 19],[\mathrm{S} 28],[\mathrm{S} 56],[\mathrm{S} 58],[\mathrm{S} 59],[\mathrm{S} 63],[\mathrm{S} 65],} \\
{[\mathrm{S} 66],[\mathrm{S} 76]} \\
{[\mathrm{S} 8],[\mathrm{S} 24],[\mathrm{S} 34],[\mathrm{S} 35],[\mathrm{S} 38],[\mathrm{S} 41],[\mathrm{S} 85],[\mathrm{S} 99],} \\
{[\mathrm{S} 102]} \\
{[\mathrm{S} 37],[\mathrm{S} 49],[\mathrm{S} 96]} \\
{[\mathrm{S} 78],[\mathrm{S} 94]} \\
{[\mathrm{S} 1],[\mathrm{S} 79]} \\
{[\mathrm{S} 11],[\mathrm{S} 77]} \\
{[\mathrm{S} 18],[\mathrm{S} 62]} \\
{[\mathrm{S} 16],[\mathrm{S} 70]} \\
{[\mathrm{S} 42]} \\
{[\mathrm{S} 74]} \\
{[\mathrm{S} 3]}\end{array}$ \\
\hline Testing & $\begin{array}{l}\text { Stimulate defect log } \\
\text { Engage and motivate to perform activities } \\
\text { Update traceability matrix } \\
\text { Improve the quality of work performed } \\
\text { Obtain user feedback }\end{array}$ & $\begin{array}{l}5 \\
5 \\
2 \\
2 \\
1\end{array}$ & $\begin{array}{l}\text { [S65], [S77], [S80], [S91], [S95] } \\
\text { [S12], }[\mathrm{S} 15],[\mathrm{S} 37],[\mathrm{S} 84],[\mathrm{S} 86] \\
{[\mathrm{S} 78],[\mathrm{S} 94]} \\
{[\mathrm{S} 2],[\mathrm{S} 26]} \\
{[\mathrm{S} 50]}\end{array}$ \\
\hline $\begin{array}{l}\text { Support } \\
\text { Processes }\end{array}$ & $\begin{array}{l}\text { Support in the execution of agile process } \\
\text { Improve the process } \\
\text { Engage and motivate to perform activities }\end{array}$ & 12 & $\begin{array}{l}\text { [S4], [S10], [S13], [S22], [S30], [S45], [S48], [S52], } \\
\text { [S57], [S64], [S69], [S83], [S101], [S103] } \\
{[\mathrm{S} 23],[\mathrm{S} 26],[\mathrm{S} 39],[\mathrm{S} 40],[\mathrm{S} 43],[\mathrm{S} 60],[\mathrm{S} 71],} \\
\text { [S73], [S89], [S91], [S92], [S93] } \\
{[\mathrm{S} 67]}\end{array}$ \\
\hline
\end{tabular}


Regarding the Requirements-related activities, the improvement of stakeholder engagement during requirements eliciting activities was the most cited benefit. Studies such as the ones published by Lombriser et al. [S51] and by Ribeiro et al. [S54] advocated that the use of gamification is a positive influence on the requirements gathering process, making those involved more participatory and consequently generating requirements with higher quality.

As an activity that is sometimes ignored and considered to be less motivating, code review was the most supported activity among Development activities. As examples, we can mention the studies published by Arai et al. [S6] and by Unkelos-Shpigel and Hadar [S58], in which gamification encouraged developers to revise the codes.

On the Testing activities, gamification acted more as a way to stimulate the registration of defects, and also as an engaging and motivating factor to perform activities. For the first case, we can mention the study by Lotufo et al. [S95], which showed that gamification encouraged team members to increase the quantity and quality of defect records. For the second case, we can mention the study published by Kohl [S84] which discussed the use of gamification as a tool to increase engagement, creativity, productivity, and fun in testing activities.

Last but not least, regarding Support Processes, gamification supported the execution of agile processes and also the process improvement. In the first case, taking the study of Yilmaz and OConnor [S10] as an example, gamification supported the execution and also in the improvement of agile processes. Note that the number of studies relating gamification with agile processes is interesting; possibly due to the flexibility and adaptivity of agile process, they better accommodate the elements included by gamification. In the second case, as in studies published by Uskarci and Demirörs [S23], Herranz et al. [S26] and Ruiz et al. [S39], gamification supported the execution of activities indicated in the process maturity models, thus supporting the improvement of the process itself.

In addition to all unique benefits of each activity, two generic benefits have been reported in more than one activity: engagement and motivation to perform activities, and improvement of the quality of the performed work. In addition to all occurrences in all activities, the engagement and motivation to perform activities was the most common benefit; it was cited in 23 studies. On the other hand, 8 studies cited improvement of the quality of work performed as a benefit achieved by gamification.

\subsection{1. (RQ2.1) Which CMMI 2.0 Practice Areas have been impacted by gamification?}

The purpose of this sub-question was to identify what activities were supported by gamification and how they are related to process improvement activities. For this, the international model CMMI [42, in its version 2.0 launched in the first semester of 2018, was used as a reference. The objective was to map the activities supported by gamification to the Practice Areas (PA) of the guide, which can be seen in the first column of Table 11. Once again, note that a study may be related to more than one PA. The number of studies per Practice Area is also shown in Figure 7 in order to make it easier to compare the distribution of studies per Practice Area.

From Table 11 and Figure 7, the contribution of gamification to designing and coding activities is substantial. This is clear from the number of studies associated with the Tech- 
Table 11: CMMI Practice Areas impacted by gamification.

\begin{tabular}{|c|c|c|}
\hline Practice Area - PA & Number & Studies \\
\hline Requirements development and management (RDM) & 22 & $\begin{array}{l}\left.\text { [S2], [S14], [S20], [S21], [S25], [S27], [S29], [S31], }{ }^{\mathrm{S}} 32\right], \\
\left.\text { [S36], [S47], }[\mathrm{S} 51], \text { [S53], [S54], [S55], [S61], [S72], }{ }^{\mathrm{S}} 755\right] \\
{[\mathrm{S} 81],[\mathrm{S} 82],[\mathrm{S} 87],[\mathrm{S} 90]}\end{array}$ \\
\hline Process quality assurance (PQA) & 9 & [S23], [S26], [S39], [S40], [S60], [S89], [S91], [S92], [S93] \\
\hline Verification and validation (VV) & 27 & $\begin{array}{l}\text { [S2], [S6], [S11], [S12], [S15], [S16], [S19], [S26], [S28], } \\
\text { [S37], [S50], [S56], [S58], [S59], [S63], [S65], [S66], [S70], } \\
{[\mathrm{S} 76],[\mathrm{S} 77],[\mathrm{S} 78],[\mathrm{S} 80],[\mathrm{S} 84],[\mathrm{S} 86],[\mathrm{S} 91],[\mathrm{S} 94], \text { [S95] }}\end{array}$ \\
\hline Peer reviews $(\mathrm{PR})$ & 5 & [S19], [S56], [S58], [S66], [S76] \\
\hline Technical solution (TS) & 31 & $\begin{array}{l}\text { [S1], [S3], [S8], [S11], [S18], [S24], [S28], [S34], [S35], } \\
\text { [S37], [S38], [S41], [S42], [S49], [S56], [S58], [S62], [S63], } \\
\text { [S65], [S66], [S74], [S76], [S77], [S78], [S79], [S85], [S88], } \\
\text { [S94], [S96], [S99], [S102] }\end{array}$ \\
\hline Product integration (PI) & 27 & $\begin{array}{l}\text { [S1], [S3], [S8], [S11], [S24], [S28], [S34], [S35], [S37], } \\
\text { [S38], [S41], [S42], [S56], [S58], [S65], [S66], [S74], [S76], } \\
\text { [S77], [S78], [S79], [S85], [S88], [S94], [S96], [S99], [S102] }\end{array}$ \\
\hline Supplier agreement management (SAM) & 0 & \\
\hline Estimating (EST) & 1 & [S68] \\
\hline Planning (PLAN) & 8 & [S2], [S7], [S33], [S34], [S68], [S98], [S100], [S103] \\
\hline Monitor and control (MC) & 14 & $\begin{array}{l}\text { [S2], [S7], [S9], [S17], [S33], [S34], [S41], [S44], [S46], } \\
{[\mathrm{S} 68],[\mathrm{S} 97],[\mathrm{S} 98],[\mathrm{S} 100],[\mathrm{S} 103]}\end{array}$ \\
\hline Risk and opportunity management (RSK) & 1 & [S5] \\
\hline Organizational training $(\mathrm{OT})$ & 0 & \\
\hline Causal analysis and resolution (CAR) & 0 & \\
\hline Decision analysis and resolution (DAR) & 0 & \\
\hline Configuration management (CM) & 3 & [S67], [S74], [S102] \\
\hline Governance (GOV) & 0 & \\
\hline Implementation infrastructure (II) & 0 & \\
\hline Process management (PCM) & 25 & $\begin{array}{l}\text { [S4], [S10], [S13], [S22], [S23], [S26], [S30], [S39], [S43], } \\
\text { [S45], [S48], [S52], [S57], [S60], [S64], [S69], [S71], [S73], } \\
{[\mathrm{S} 83],[\mathrm{S} 89],[\mathrm{S} 91],[\mathrm{S} 92],[\mathrm{S} 93],[\mathrm{S} 101],[\mathrm{S} 103]}\end{array}$ \\
\hline Process asset development (PAD) & 0 & \\
\hline Managing performance and measurement (MPM) & 0 & \\
\hline
\end{tabular}

nical solution (TS) and Product integration (PI) PAs. Within this group, for example, there are studies that dealt with code improvement and documentation. There are 3 studies associated with the Configuration management (CM) PA, which addressed the activities in the version control systems. There are also some studies that dealt with code review; those are associated with Verification and Validation (VV), and Peer reviews (PR).

In addition to the code review studies, several studies supporting test activities were also mapped in the Verification and validation (VV) PA. Most of them dealt with improved defect registration.

The gamification support for the requirements-related activities is represented by the Requirements development and management (RDM) PA. It emphasizes the prioritization of requirements and, mainly, the improvement of stakeholder involvement.

Project management activities were mapped into the Planning (PLAN), Monitor and 


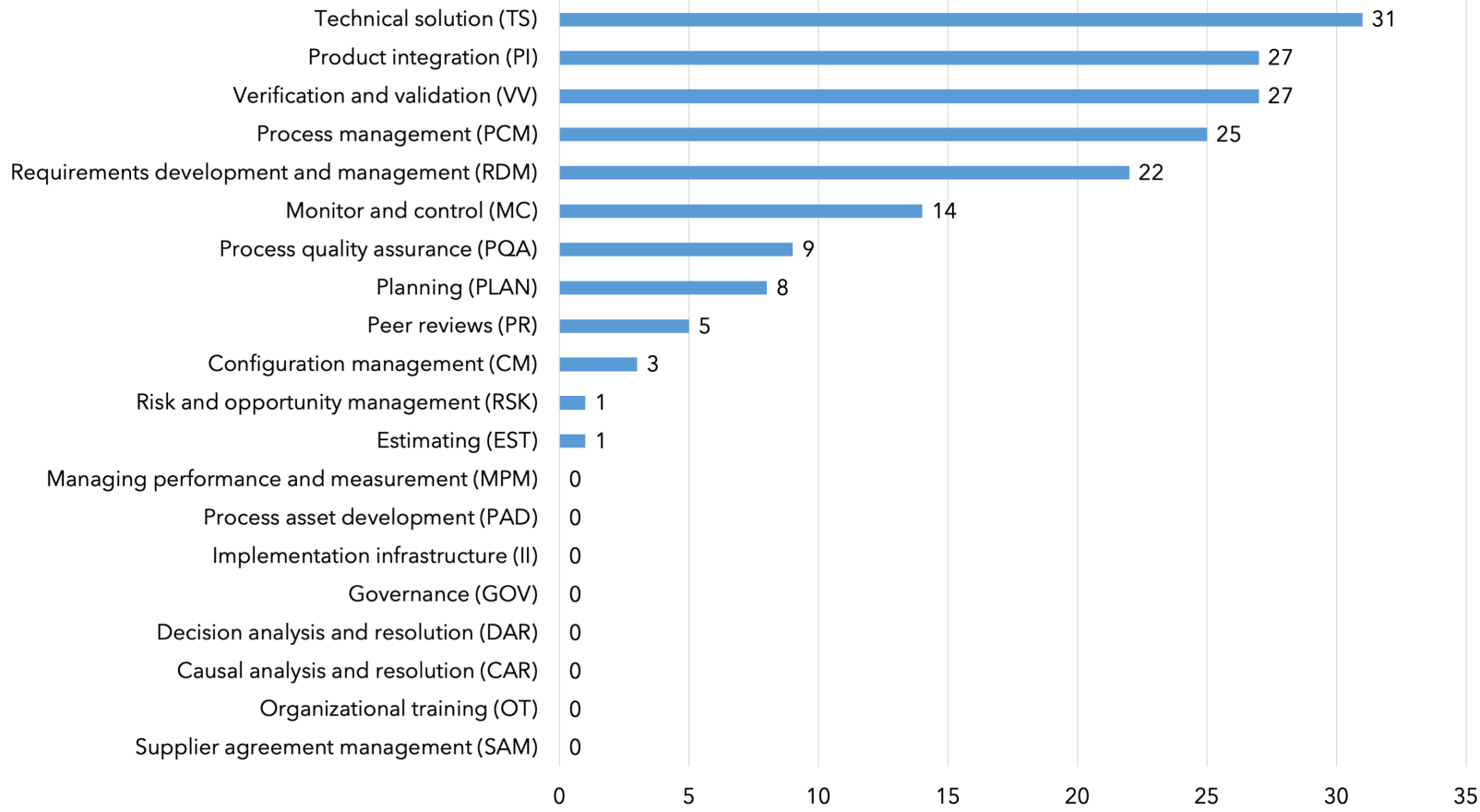

Figure 7: CMMI Practice Areas impacted by gamification

control (MC), Estimating (EST), and Risk and opportunity management (RSK) PAs. In general, these studies focused on improving the engagement and motivation of teams. There are studies that dealt with the distribution of activities, and also with risk assessment and mapping.

The Process management (PCM) and Process quality assurance (PQA) PAs mapped the studies related to process management. These studies dealt with improvements in processes through the execution of activities defined in maturity models. It is worth mentioning the large number of studies that explored gamification as a mechanism to support and improve agile processes.

Eight PAs (namely, Supplier agreement management (SAM), Organizational training (OT), Causal analysis and resolution (CAR), Decision analysis and resolution (DAR), Governance (GOV), Implementation infrastructure (II), Process asset development (PAD), and Managing performance and measurement (MPM)) could not be mapped to any study. Naturally, studies that would fit into Organizational training (OT) were excluded by the e1 exclusion criterion (namely, Considers gamification in the educational or training context), while the other PAs were excluded because they are not software engineering end activities (exclusion criteria e3). Despite this, there is no real impediment to the application of gamification to support activities related do those PAs.

Revisiting our research question RQ2, the benefits of gamification in software development activities can be clearly seen in Table 10. Through Table 11 it is also clear that, so far, 
gamification has covered a considerable amount of Practice Areas defined in CMMI 2.0. In this research, disregarding the studies discarded by the exclusion criteria, it can be seen that existing research on gamification to support software engineering tasks can be mapped to 60\% (12 of 20) of CMMI Practice Areas.

\section{4. (RQ3) Which software has supported the gamification implementation and in which} contexts it has been used?

To answer RQ3, we identified the tools (software) that were used to support the application of gamification in software engineering. From the 103 selected studies, 57 explicitly mentioned this type of support. Table 12 shows all identified tools grouped by activity and benefit.

In Table 12 it is possible to identify the type of the tool. Gamified tools are marked with the symbol, while tools enabling gamification are identified with the symbol. In the table, it is possible to identify that the vast majority of tools are gamified. Another interesting fact is the small number of tools that have declared themselves as open-source. It is possible that more tools are open-source, but only six made that clear. A remarkable feature of the identified tools is that the vast majority are available on the web platform (symbol 3). Only two tools are available on the mobile platform (symbol $\mathbf{0}$ ). Six tools are desktop (symbol $\square$ ) and all of them are related to development activities since most of these tools are integrated with the IDEs used by programmers. Five tools do not make it clear on which platform they are available and were marked with the $\mathbf{P}$ symbol. From all tools, only seven indicated a web address ${ }^{9}$ where they can be found.

According to Table 12, most of the identified tools support software development activities. Despite this, among the identified tools we highlight DMGame, Garuso and Gamiware that were either presented or used in more studies (4 each, in total). DMGame and Garuso are gamified tools while Gamiware is at same time a gamified tool and a tool enabling gamification.

\subsection{RQ4. What are the challenges and difficulties of deploying gamification in software engineering?}

As already shown in Table 5 , a substantial number of studies were classified as proposals of solutions. Table 6 shows a high number of studies with no experimental evaluation carried out. Indeed, the majority of the selected studies presented research in very early stage and did not address any type of difficulties and challenges on the implementation of gamification. More precisely, 65 studies addressed specific problems in which gamification can help,

\footnotetext{
${ }^{9}$ RE-PROVO: http://egov-requirements.org GamifiedSD : https://github.com/skbly7/ gamifiedSD GithubCC: https://github.com/tzachz/github-comment-counter Stack overflow: www.stackoverflow.com; G-Unit: https://github.com/davidarnarsson/Gunit/Mozilla Open Badges: https://openbadges.org, and Habitica: https://habitica.com-accessed on 13-September-2020.
} 
Table 12: Tools that support gamification.

\begin{tabular}{|c|c|c|c|c|c|c|}
\hline Activity & Benefit & Tool & Studies & Type & $\begin{array}{l}\text { Open } \\
\text { Source }\end{array}$ & $\begin{array}{l}\text { Plat } \\
\text { form }\end{array}$ \\
\hline \multirow{3}{*}{ Requirements } & $\begin{array}{l}\text { Improve the engagement of } \\
\text { stakeholders }\end{array}$ & $\begin{array}{l}\text { Agon } \\
\text { MAF }\end{array}$ & $\begin{array}{l}{[\mathrm{S} 14],[\mathrm{S} 47]} \\
{[\mathrm{S} 47]}\end{array}$ & $\cot ^{*}$ & & 2 \\
\hline & $\begin{array}{l}\text { Facilitate requirements } \\
\text { prioritization }\end{array}$ & $\begin{array}{l}\text { DMGame } \\
\text { Garuso } \\
\text { GRP }\end{array}$ & $\begin{array}{l}{[\mathrm{S} 27],[\mathrm{S} 29],[\mathrm{S} 36],[\mathrm{S} 53]} \\
{[\mathrm{S} 21],[\mathrm{S} 55],[\mathrm{S} 61],[\mathrm{S} 87]} \\
{[\mathrm{S} 90]}\end{array}$ & $\begin{array}{c}\infty \\
\mathbf{\infty} \\
+\end{array}$ & & \\
\hline & $\begin{array}{l}\text { Improve the participation in a } \\
\text { collaborative requirements } \\
\text { elicitation }\end{array}$ & $\begin{array}{l}\text { iThink } \\
\text { REfine } \\
\text { RE-PROVO } \\
\text { REVISE }\end{array}$ & $\begin{array}{l}{[\mathrm{S} 54],[\mathrm{S} 55],[\mathrm{S} 75]} \\
{[\mathrm{S} 32],} \\
{[\mathrm{S} 552],} \\
{[\mathrm{S} 72]}\end{array}$ & $\begin{array}{l}\infty \\
\infty \\
\infty\end{array}$ & & \\
\hline \multirow{6}{*}{ Development } & Encourage code review & $\begin{array}{l}\text { CRA } \\
\text { CARE } \\
\text { CodeBrag } \\
\text { GamifiedSD } \\
\text { GithubCC } \\
\text { SCRUT } \\
\end{array}$ & $\begin{array}{l}{[\mathrm{S} 28]} \\
{[\mathrm{S} 56]} \\
{[\mathrm{S} 66]} \\
{[\mathrm{S} 66]} \\
{[\mathrm{S} 66]} \\
{[\mathrm{S} 58]}\end{array}$ & $\begin{array}{l}\infty \\
\infty \\
\infty \\
\infty \\
\infty \\
\infty\end{array}$ & $\begin{array}{l}\mathrm{Y} \\
\mathrm{Y} \\
\mathrm{Y}\end{array}$ & ? \\
\hline & $\begin{array}{l}\text { Encourage good programming } \\
\text { practices }\end{array}$ & $\begin{array}{l}\text { Themis } \\
\text { Blaze } \\
\text { Teamfeed } \\
\text { OO Practices } \\
\text { Beehive }\end{array}$ & $\begin{array}{l}{[\mathrm{S} 37],[\mathrm{S} 49]} \\
{[\mathrm{S} 8],[\mathrm{S} 35]} \\
{[\mathrm{S} 8],[\mathrm{S} 74]} \\
{[\mathrm{S} 8]} \\
{[\mathrm{S} 8]}\end{array}$ & $\begin{array}{l}\infty \\
\infty \\
\infty \\
\infty \\
\infty\end{array}$ & & \\
\hline & Encourage code refactoring & $\begin{array}{l}\text { CodeArena } \\
\text { GBC }\end{array}$ & $\begin{array}{l}{[\mathrm{S} 3]} \\
{[\mathrm{S} 6]}\end{array}$ & $\mathbf{\infty}$ & & \\
\hline & $\begin{array}{l}\text { Improve software } \\
\text { documentation }\end{array}$ & $\begin{array}{l}\text { AKB } \\
\text { CollabReview } \\
\text { QuoDocs }\end{array}$ & $\begin{array}{l}{[\mathrm{S} 88]} \\
{[\mathrm{S} 1]} \\
{[\mathrm{S} 79]}\end{array}$ & $\begin{array}{l}\mathbf{6 0} \\
\mathbf{6} \\
\mathbf{6 0}\end{array}$ & & \\
\hline & Update traceability matrix & $\begin{array}{l}\text { Eclipse Capra } \\
\text { GamiTracify }\end{array}$ & $\begin{array}{l}{[\mathrm{S} 67]} \\
{[\mathrm{S} 78]}\end{array}$ & $\mathbf{\infty}$ & & \\
\hline & $\begin{array}{l}\text { Encourages knowledge ex- } \\
\text { change between developers }\end{array}$ & stack overflow & [S8], [S95] & $\boldsymbol{\infty}$ & & \\
\hline Testing & $\begin{array}{l}\text { Engage and motivate to } \\
\text { perform test activities }\end{array}$ & $\begin{array}{l}\text { G-Unit } \\
\text { Rank-Me }\end{array}$ & $\begin{array}{l}{[\mathrm{S} 70]} \\
{[\mathrm{S} 80]}\end{array}$ & $\mathbf{\infty}$ & $\mathrm{Y}$ & \\
\hline $\begin{array}{l}\text { Project } \\
\text { Management }\end{array}$ & $\begin{array}{l}\text { Facilitate activities } \\
\text { distribution and control }\end{array}$ & $\begin{array}{l}\text { Agile Workbench } \\
\text { RUPGY } \\
\text { DevRPG } \\
\text { Scraim } \\
\text { Trogon }\end{array}$ & $\begin{array}{l}{[\mathrm{S} 4],[\mathrm{S} 13]} \\
{[\mathrm{S} 22],[\mathrm{S} 103]} \\
{[\mathrm{S} 98]} \\
{[\mathrm{S} 41]} \\
{[\mathrm{S} 46]}\end{array}$ & $\begin{array}{l}\infty \\
60 \\
60 \\
\oplus 0 \\
\oplus 0\end{array}$ & & \\
\hline \multirow{2}{*}{$\begin{array}{l}\text { Support } \\
\text { Processes }\end{array}$} & $\begin{array}{l}\text { Support in software process } \\
\text { improvement }\end{array}$ & $\begin{array}{l}\text { GamiSPI } \\
\text { SysDyn }\end{array}$ & $\begin{array}{l}{[\mathrm{S} 71]} \\
{[\mathrm{S} 39]}\end{array}$ & $\mathbf{\infty}$ & & \\
\hline & $\begin{array}{l}\text { Support in the execution of } \\
\text { agile process }\end{array}$ & $\begin{array}{l}\text { SD project gamification } \\
\text { Gaming Scrum } \\
\text { XGamify }\end{array}$ & $\begin{array}{l}{[\mathrm{S} 44]} \\
{[\mathrm{S} 101]} \\
{[\mathrm{S} 57]}\end{array}$ & $\begin{array}{l}\mathbf{\infty} \\
\mathbf{\infty} \\
\mathbf{6}\end{array}$ & & \\
\hline $\begin{array}{l}\text { General } \\
\text { Activities }\end{array}$ & $\begin{array}{l}\text { Generic support for } \\
\text { gamification insertion }\end{array}$ & $\begin{array}{l}\text { Gamiware } \\
\text { Mozilla Open Badges } \\
\text { GOAL } \\
\text { Habitica } \\
\text { OpenBadgesUCA } \\
\text { GamAnalyze }\end{array}$ & $\begin{array}{l}\text { [S26], [S40], [S60], [S73] } \\
\text { [S97] } \\
\text { [S2] } \\
\text { [S8], [S68] } \\
\text { [S39] } \\
{[\mathrm{S} 39]}\end{array}$ & $\begin{array}{l}\omega \\
+\infty \\
+\infty \\
6 \\
\infty\end{array}$ & $\begin{array}{l}\mathrm{Y} \\
\mathrm{Y}\end{array}$ & \\
\hline
\end{tabular}


without clearly addressing the challenges and difficulties of implementing the gamification itself. On the other hand, 44 studies already pointed out difficulties and challenges for implementing gamification. The items identified in these 44 studies are listed in Table 13 .

Table 13: Challenges and difficulties of implementing gamification.

\begin{tabular}{|c|c|c|}
\hline Challenges and difficulties & Number & Studies \\
\hline $\begin{array}{l}\text { Fair assignment of points or reward and, at the same time, enjoyable } \\
\text { to the players }\end{array}$ & 9 & $\begin{array}{l}{[\mathrm{S} 1],[\mathrm{S} 11],[\mathrm{S} 28],[\mathrm{S} 37],[\mathrm{S} 69],[\mathrm{S} 70],} \\
{[\mathrm{S} 74],[\mathrm{S} 80],} \\
{[\mathrm{S} 97]}\end{array}$ \\
\hline Conducting empirical studies & 9 & 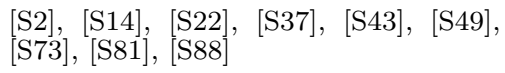 \\
\hline Implementation of the tool or gamified environment & 7 & $\begin{array}{l}{[\mathrm{S} 2],[\mathrm{S} 14],[\mathrm{S} 19],[\mathrm{S} 65],[\mathrm{S} 68],[\mathrm{S} 70],} \\
{[\mathrm{S} 75]}\end{array}$ \\
\hline Cheats & 6 & {$[\mathrm{~S} 3],[\mathrm{S} 16],[\mathrm{S} 25],[\mathrm{S} 26],[\mathrm{S} 99],[\mathrm{S} 102]$} \\
\hline Find elements of gamification that motivate the whole team & 4 & {$[\mathrm{~S} 32],[\mathrm{S} 41],[\mathrm{S} 77],[\mathrm{S} 78]$} \\
\hline $\begin{array}{l}\text { Changing the focus of the activity: Having a better score is more } \\
\text { important than having the activity performed }\end{array}$ & 4 & [S12], [S16], [S32], [S102] \\
\hline People demotivation & 4 & {$[\mathrm{~S} 1],[\mathrm{S} 32],[\mathrm{S} 39],[\mathrm{S} 48]$} \\
\hline Commitment of top-managers & 3 & {$[\mathrm{~S} 26],[\mathrm{S} 71],[\mathrm{S} 97]$} \\
\hline Find elements that motivate the long term & 3 & {$[\mathrm{~S} 46],[\mathrm{S} 81],[\mathrm{S} 97]$} \\
\hline People stressed with the competitiveness generated by gamification & 2 & {$[\mathrm{~S} 6],[\mathrm{S} 60]$} \\
\hline Fear with data privacy & 2 & {$[\mathrm{~S} 12],[\mathrm{S} 37]$} \\
\hline Decrease people's creativity & 2 & {$[\mathrm{~S} 25],[\mathrm{S} 31]$} \\
\hline Integrate the tool with the company's existing tools & 2 & {$[\mathrm{~S} 26],[\mathrm{S} 47]$} \\
\hline Atmosphere to be impersonal: people stop interacting in person & 2 & {$[\mathrm{~S} 51],[\mathrm{S} 90]$} \\
\hline Decreases autonomy & 1 & {$[\mathrm{~S} 35]$} \\
\hline Find professionals with experience in gamification & 1 & {$[\mathrm{~S} 40]$} \\
\hline Motivating women & 1 & {$[\mathrm{~S} 8]$} \\
\hline Segregate people into groups & 1 & {$[\mathrm{~S} 25]$} \\
\hline
\end{tabular}

As shown in the Table 13, one of the main challenges reported by the studies was finding a fair assignment of points or reward. This was not simple for 9 studies. At the same time, since people and teams have different personalities, finding the ideal elements that motivate everyone was also cited as a difficult factor in 4 studies. The question of the motivation period was quoted in three studies, which report that, over time, the gamification elements loose their motivating effect.

Another major difficulty was the execution of experimental studies. Finding a company ready to conduct experimental studies seems to be a very important factor since we found a low number of evaluation studies ( $c f$. Table 5 ). Next to this, it was also mentioned the lack of commitment of top-managers, turning it difficult to implement gamification in the real environment.

Other difficulty pointed out was the implementation of a tool or a gamified environment. Automation was always a pursued goal, however the construction of tools is far from being trivial, especially considering the integration between the gamified environment and the tools already existing in the company. 
Regarding the level of motivation, even though one can have a good choice for gamification elements, and consequently succeed in motivating everyone, "excessive motivation" should be carefully considered. In some cases, for example, it was related to situations where people cheated to improve their score. In other cases, there was an inversion of values: having a good score became more important than doing the final activity. In other cases, yet, the environment became impersonal and this led to some people to stop interacting in person and beginning to do so only through the tools.

Another point also cited as hard is the excess of competitiveness generated by gamification. In some cases, the competition made some people feeling stressed and unmotivated. In other cases, this excess was enough to segregate people into groups, which in turn became competitors, thus reducing the collaboration between them. Yet in other cases, people's creativity was reduced as they became more involved and focused on the elements of games.

Finally, the difficulty in finding professionals with experience in gamification, and the greater difficulty in motivating women, were also remembered among the challenge factors and difficulties to introduce gamification.

Thus, revisiting our research question RQ4, based on the results summarized in Table 13 , we conclude that there are still a considerable number of challenges and difficulties inherent in the gamification implementation process. Any initiative in the direction of insertion of gamification should take into consideration the items presented as results for this research question.

\subsection{Evaluating the mapping process}

This section presents the application of the evaluation rubric proposed by Petersen et al. [36]. The evaluation rubric contains 26 actions to be taken when a systematic mapping is performed. Table 14 shows all the actions suggested in the rubric. The actions taken are marked with the symbol and represent more than $53 \%$ of the total suggested actions. Tables 15,19 presents the scoring rubrics. The scores identified in this mapping study are highlighted with an $*$.

It is important to note that in this systematic mapping a quality assessment was not carried out on the selected studies. As Petersen et al. [36] argue, the quality assessment is more essential in systematic reviews to determine the rigor and relevance of the primary studies. In systematic maps no quality assessment needs to be performed. If we consider the Wieringa et al. [40]'s research types classification, the category of solution proposals would contain papers with no empirical evidence. Even though such studies would not be included in a systematic review, they are important to spot trends of topics under investigation in systematic maps [36].

\section{Research Implications}

This section presents a compilation concerning the use of gamification in the software engineering context. In addition, it presents how gamification has been used to achieve the 
Table 14: Activities conducted in this research.

\begin{tabular}{|c|c|c|}
\hline Phase & Actions & Applied \\
\hline Need for map & $\begin{array}{l}\text { Motivate the need and relevance } \\
\text { Define objectives and questions } \\
\text { Consult with target audience to define questions }\end{array}$ & $\ddot{\bullet}$ \\
\hline Study ident. & $\begin{array}{l}\text { Choosing search strategy } \\
\text { Snowballing } \\
\text { Manual } \\
\text { Conduct database search } \\
\text { Develop the search } \\
\text { PICO } \\
\text { Consult librarians or experts } \\
\text { Iteratively try finding more relevant papers } \\
\text { Keywords from known papers } \\
\text { Use standards, encyclopedias, and thesaurus } \\
\text { Evaluate the search } \\
\text { Test-set of known papers } \\
\text { Expert evaluates result } \\
\text { Search web-pages of key authors } \\
\text { Test-retest } \\
\text { Inclusion and Exclusion } \\
\text { Identify objective criteria for decision } \\
\text { Add additional reviewer, resolve disagreements between them when needed } \\
\text { Decision rules }\end{array}$ & $\begin{array}{l}0 \\
- \\
- \\
- \\
- \\
- \\
0 \\
- \\
- \\
- \\
0 \\
0 \\
0\end{array}$ \\
\hline Data extr. and class. & $\begin{array}{l}\text { Extraction process } \\
\text { Identify objective criteria for decision } \\
\text { Obscuring information that could bias } \\
\text { Add additional reviewer, resolve disagreements between them when needed } \\
\text { Test-retest } \\
\text { Classification scheme } \\
\text { Research type } \\
\text { Research method } \\
\text { Venue type }\end{array}$ & $\begin{array}{l}- \\
- \\
- \\
0 \\
0 \\
0\end{array}$ \\
\hline Validity discussion & Validity discussion/limitations provided & 0 \\
\hline
\end{tabular}

Table 15: Rubric: need for review.

\begin{tabular}{lll}
\hline Evaluation & Description & Score \\
\hline No description & The study is not motivated and the goal is not stated & 0 \\
Partial evaluation & Motivations and questions are provided & $1^{*}$ \\
Full evaluation & Motivations and questions are provided, and have been defined in correspondence & 2 \\
& with target audience & \\
\hline
\end{tabular}

Table 16: Rubric: choosing the search strategy.

\begin{tabular}{lll}
\hline Evaluation & Description & Score \\
\hline No description & Only one type of search has been conducted & 0 \\
Minimal evaluation & Two search strategies have been used & $1^{*}$ \\
Full evaluation & All three search strategies have been used & 2 \\
\hline
\end{tabular}

Table 17: Rubric: evaluation of the search.

\begin{tabular}{lll}
\hline Evaluation & Description & Score \\
\hline No description & $\begin{array}{l}\text { No actions have been reported to improve the reliability of the search and inclu- } \\
\text { sion/exclusion }\end{array}$ & 0 \\
Minimal evaluation & $\begin{array}{l}\text { At least one action has been taken to improve the reliability of the search xor the } \\
\text { reliability of the inclusion/exclusion }\end{array}$ & 1 \\
Partial evaluation & $\begin{array}{l}\text { At least one action has been taken to improve the reliability of the search and the } \\
\text { inclusion/ exclusion }\end{array}$ & $2^{*}$ \\
Full evaluation & All actions identified have been taken & 3 \\
\hline
\end{tabular}


Table 18: Rubric: extraction and classification.

\begin{tabular}{lll}
\hline Evaluation & Description & Score \\
\hline No description & No actions have been reported to improve on the extraction process or enable com- & 0 \\
Minimal evaluation & parability between studies through the use of existing classifications & \\
Partial evaluation & At least one action has been taken to increase the reliability of the extraction process & 1 \\
& and research type and meen taken to increase the reliability of the extraction process, & $2^{*}$ \\
Full evaluation & All actions identified have been taken & 3 \\
\hline
\end{tabular}

Table 19: Rubric: study validity.

\begin{tabular}{lll}
\hline Evaluation & Description & Score \\
\hline No description & No threats or limitations are described & 0 \\
Full evaluation & Threats and limitations are described & $1^{*}$ \\
\hline
\end{tabular}

proposed goals. For each presented topic in this section, we discuss the potential contexts not yet explored with the application of gamification.

\subsection{Requirements}

Regarding the requirements topic, most of the selected studies ([S2], [S14], [S20], [S25], [S31], [S32], [S47], [S51], [S54], [S55], [S61], [S72], [S75], [S81], [S82], [S87]) explored gamification as a facilitator for the requirements elicitation process. In these studies, the gamification elements were used to encourage the participation of stakeholders, making them more committed to the elicited requirements, specially when they were geographically distributed. Consequently, more requirements were elicited, and with better quality.

The main gamification elements used to assist the requirements elicitation process were points, leaderboards, and levels. They were useful to motivate the stakeholders to propose new requirements, stimulate comments and discussions about the requirements aiming at improving their precision.

In addition, gamification was explored in the requirements prioritization context. Some studies ([S21], [S27], [S29], [S36], [S53], [S90]) pointed to the use of gamification elements to encourage stakeholders to agree with each other, and to speed up the creation of prioritized lists of requirements.

Research opportunities: There are areas already explored within the requirements elicitation process. However, we noticed a lack of studies that applied gamification to motivate and improve requirements writing and documentation, and studies that deal with modeling the requirements in diagrams. In addition, although the management of changes and the maintenance of traceability between artifacts have been used in other activities in the software development life cycle, these activities were not explored in the studies related to requirements.

\subsection{Development}

Activities of development and coding represent other topic related to gamification. There are several ways in which the development process can benefit from gamification. All of them 
aim at making the process easier, and at delivering a higher quality source code. The main gamification elements used in this scenario were points, leaderboards, and badges.

Most studies related to development have the direct objective of improving the quality of the developed code. Some studies ([S16], [S65], [S70]) explored the use of gamification for the creation and execution of unit tests. In studies [S49] and [S42], gamification was used to encourage the removal of technical debits and adherence to code conventions, respectively.

Inspection and code review are other major software development activities addressed by gamification. These activities, sometimes considered boring, time consuming, unattractive, but directly related to code quality, were the target of several studies ([S19], [S28], [S56], [S58], [S59], [S66], [S76]).

In addition to code review, refactoring is another aspect directly related to code quality. Some studies ([S3], [S6]) described the use of gamification to incentive and motivate a constant code refactoring aiming at making the code lesser complex, updated, and with higher quality. These activities were often encouraged by inserting gamification into the IDEs. Besides this, some studies ([S3], [S8], [S96]) speculated for more interesting results when inserting gamification elements as close as possible to the developers' environment (IDEs).

Some studies ([S8], [S18], [S24], [S38], [S62], [S63], [S77], [S99]) used the gamification elements to keep developers engaged and motivated while performing their programming tasks. Other ways of using gamification is to ensure a coding standardization or to adopt good programming practices. Specifically, some studies ([S35], [S37], [S41], [S74], [S96], [S102]) applied gamification to encourage desirable good practices such as an adoption of new tools and also frequent commit in version control tools. In this case, in addition to good practices, gamification also supported the configuration management of the artifacts.

Documentation, as an often ignored activity by many programmers, was also a target of gamification. A subset of the selected studies ([S1], [S78], [S79], [S94]) pointed to the use of gamification elements as a way of documenting artifacts, mostly as code comments. Maintaining a traceability matrix between code and test cases was also reported and fits into this category.

Research opportunities: Despite all this range of presented possibilities, we noticed gamification has not been explored to support for other activities related to the development phase. While coding activities are well supported by gamification, design activities remain disregarded. Activities related to software modeling and architecture, project-level documentation and the use of design patterns were not directly explored in the selected studies. Another relevant point regards software maintenance. While refactoring has been explored in many studies, reengineering has also been disregarded.

\subsection{Testing}

Regarding testing-related activities, the main gamification elements (points and leaderboards) were used as a stimulus for performing activities. Some studies ([S12], [S15], [S37], [S84], [S86]) used gamification elements to motivate and commit the team to test case generation as well as test execution. 
Another important part of the testing process is defect records. Some studies ([S65], [S80], [S95]) took advantage of gamification precisely to improve and stimulate the team in bug reporting. Obtaining user feedback is another target of gamification. In study [S50], avatar, badges, and points were used to encourage the user to provide feedback regarding the software. In that study, one of the aspects evaluated by the feedback may be the usability of the software.

Traceability supported by gamification was also explored in testing context. As examples of this, two studies ([S78], [S94]) explored gamification as a tool for maintaining defect tracking and also keeping the traceability matrix between code and defect updated.

Research opportunities: We believe there is a big gap to be investigated when it comes to software testing techniques and criteria. We did not identified any study that explicitly aimed to explore the traditional techniques such as functional, structural and fault-based testing, as well as their associated test selection criteria. Even studies that supported test case generation and test execution did not mention any of these techniques. Another identified research opportunity is regarding test types. The studies did not directly mention the types of tests being performed. With this, we can indicate as research opportunities, but not limited to this, the following types of tests: acceptance, installation, alpha and beta, usability, reliability and evaluation, regression, performance, safety, stress, and recovery.

\subsection{Project Management}

A few studies ([S2], [S41], [S68], [S97]) showed that the management of software development projects can benefit from the use of gamification, particularly in activities related to overall project monitoring and control. In those studies, the project manager used gamification elements such as points, leaderboards, levels and challenges as a way to keep the team motivated while performing their activities. Thus the team was encouraged to use the process and tools as desired by the project manager. Since the process and tools were used as planned, metrics could provide a better overview of what is going on with the project, making decision making easier ([S2], [S68]).

In addition to these studies, several others ([S5], [S34], [S41], [S44], [S46], [S97], [S98], [S103]) pointed out the use of gamification in project task management. These studies, which dealt with project scope and time control, basically used points, leaderboards, levels, and badges to control the distribution and execution of project activities. These studies largely advocated the use of gamification in task tracking and logging tools.

Another important aspect of project management is project resource control and communication. In the first case, some studies ([S7], [S33]) used gamification to perform team profile mapping, and thus the project's human resources could be more appropriately managed. In the second case, other studies ([S9], [S100]) tried to solve with gamification a serious problem in projects: the collaboration and communication between team members.

Research opportunities: Despite the support to aspects already mentioned regarding project management activities, gamification could also be explored for controlling costs, acquisitions, as well as stakeholder control. The last one only appears in stakeholder control when the requirements are raised. It is also important to remember that many studies that addressed 
project management to be applied in the context of software development may have been left out of this research because they did apply their research directly to other types of projects but software development-related ones.

\subsection{Support Processes}

Studies categorized as support process used gamification to support software development processes. These studies supported two aspects of software development. The majority of studies of this category advocated for support of gamification in the context of agile processes. Several studies ([S10], [S22], [S30], [S45], [S48], [S52], [S57], [S64], [S69], [S83], [S101], [S103]) pointed to the use of points, leaderboards, avatars, and badges as ways to motivate and encourage the team to perform software development activities in an agile context. Other studies ([S4], [S13]) used points to motivate teams to promote fast sprint delivery. In these studies, teams received points corresponding with the delivery speed of the sprint to finish the sprint before the scheduled time.

Another issue that was also widely addressed in support activities ([S23], [S26], [S39], [S40], [S43], [S60], [S71], [S73], [S89], [S92], [S93]) was the support tool for monitoring and process improvement. In these cases, simple gamification elements such as points, leaderboards, and badges were used to promote an improvement in the execution of software development activities. These studies then argued that improving the execution of each activity can improve the process as a whole.

Research opportunities: Many studies made it clear and reinforced that the application of gamification was in an agile processes. However, there is still a lack of research regarding the use of gamification in non-agile processes.

\subsection{Other General Observations and Current Research Limitations}

One way to evaluate the current research landscape and identify new opportunities is to evaluate the future research possibilities presented by the authors of the analyzed studies. Table 20 summarizes such information. The main themes presented in this table can be grouped into two distinct groups: need for further empirical studies (lines 1, 3, 5 and 6); and need for tool support and exploration of a wider range of elements (lines 2 and 7 ).

Table 20: Upcoming research presented in the studies.

\begin{tabular}{lc}
\hline Upcoming research theme & Number of studies \\
\hline Perform most significant statistical tests & 43 \\
Create / Improve tools & 24 \\
Implement the proposal / Analyze the proposal feasibility & 16 \\
Do not cite upcoming studies & 11 \\
Conduct experiments outside the academic environment & 10 \\
Probe the research / Mature the proposal & 10 \\
Explore more deep the gamification use, its elements, etc. & 8 \\
\hline
\end{tabular}

The first group presents a discomfort of the authors with the simplicity of their research. This is a point that was evident during the analysis of the selected studies. Most of them did not present data that allows for further analysis of the study. This is downside of current 
research because besides having low credibility, it does not allow replication and comparison of the achieved results.

It is also alarming the fact that many studies did not show any result, whilst others just presented preliminary results. Another point that caught our attention is that many of the studies that showed some results were conducted with students in an academic environment. When something was done in the industry, a considerable number of studies were just a survey, which was always done with a very small number of participants. Unfortunately, this is a barrier for definite conclusions on the subject, and reinforces the idea that the community still needs to deepen research on gamification in software development.

The second group focused their concerns on the study of gamification itself, on the computer-based support for gamification application, and on the best use of the elements. The use of tools for the implementation of gamification was a largely addressed issue in the studies. Although the number of studies that addressed the construction and use of tools is large, practically all studies indicated difficulties for the construction of these tools. One of the difficulties pointed out in the studies was the integration of the gamification tool with the tools already used by the teams. This is because most studies attempted to use the elements of gamification more automatically. For example, researchers did not want to keep counting participants' points manually. This really makes building tools far from trivial.

As already shown in Figure 6, most studies supported gamification with basic elements such as leaderboards, levels, badges, and (mainly) points. In general, we can notice a simple and direct application of these elements. Therefore, it is clear that there is still a long way to go for maturing gamification in the context of software development. This makes us think of the following questions:

- Can the other elements be better explored?

- Are there other elements (other than those shown in Figure 6) that can contribute to software development?

- Are the other gamification elements not used because they are more difficult to implement?

These are still open questions. They show that there is still a lot of research opportunity in this area. In general, we can summarize this whole section in Figure 8. It presents a mind map that describes which topics have already been studied with gamification, and what remains without investigation.

\section{Threats to Validity}

This section presents the possible threats associated to this SM based on the main threats defined by Zhou et al. [43].

Inappropriate research question and Incomprehensible venues or database: In this study, the research questions may not address all aspects of gamification in software 


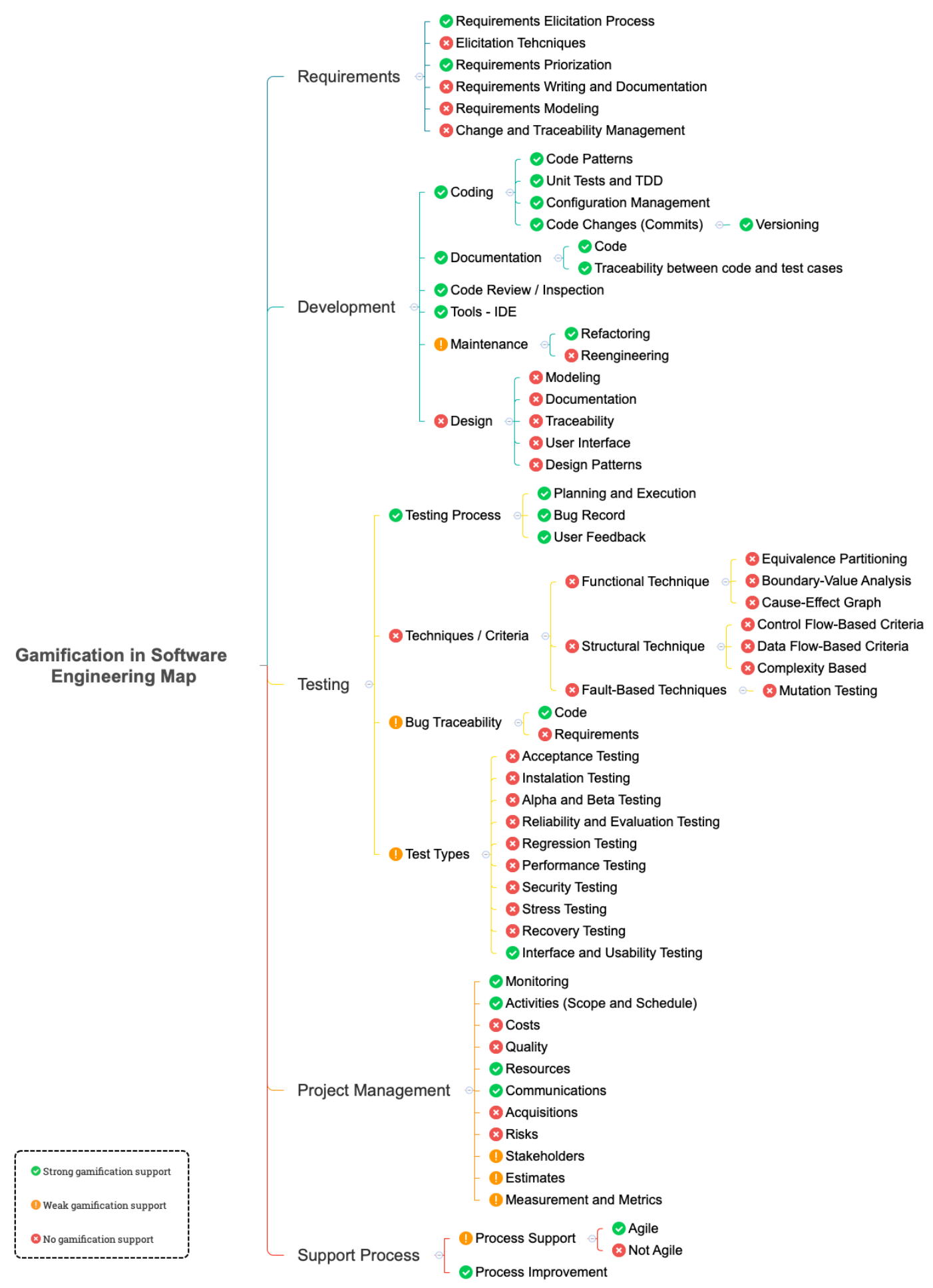

Figure 8: Map of the use of gamification in software development. 
engineering. To minimize this threat, we developed a set of research questions that explore different perspectives on the use of gamification in software engineering. Regarding the search engines and their associated databases, they are well-known sources that return studies from relevant scientific events and journals on the subject under investigation. In addition, as mentioned earlier, we tried to mitigate the possibility of a study not to be indexed in the search engines by performing a round of backward snowballing [38] in the selected studies.

Primary study duplication: We used the Start tool [39] to facilitate and decrease the chances of errors when dealing with duplicate papers. With the tool, duplicate papers are automatically removed from the list of papers.

Incorrect search method and Inappropriate or incomplete search terms in automatic search: Regarding the search string, when compared with search strings used in related studies, our string includes a larger variety of synonyms retrieved from the already known studies. To validate the string, we checked if the string was able to return all previously known studies.

Bias in study selection and Identification error of primary studies in the searching process: We must consider the subjective decisions that may have occurred during the selection of primary studies. Consequently, relevant studies might not have been selected. To minimize this threat, a rigorous plan was followed, which was guided by the well-defined inclusion and exclusion criteria that were carefully applied to the selected studies. This step was performed by an author and, when there was doubt about the criteria application, the decision was made with the support of additional authors. As a way of standardizing the application of the criteria, a round of cross-validation was carried out in which all authors received five studies and applied the criteria in the same way. In addition, to reduce fatigue and, consequently, human error, each review session lasted, at most, four hours.

Bias in data extraction, Misclassification of primary studies, and Subjective interpretation about the extracted data: We must consider the subjective decisions that may have occurred during the extraction of data. In this study, during the data extraction process, in which we established the relationships between the use of gamification and software engineering activities, a second author was consulted to mitigate doubts. When no consensus was found, a group discussion was performed until the conflicting ideas were sorted out. Regarding the mapping of the CMMI-2 areas, cross-validation was carried out. The primary studies were analyzed trying to find areas of CMMI-2 in which the studies fit, and the model was also analyzed with the aim of finding, in the primary studies, the areas described in the model. This classification was carefully done to reduce the likelihood of misclassifications. It is also worth mentioning that the conclusions drawn in this SM were made based on the reports contained in each study. Thus, only the characteristics explicitly mentioned in the studies were mapped. Another point is that many of the studies are still incipient (i.e. research in early stage). Consequently, perhaps not all benefits, difficulties, and characteristics have been clearly stated in the studies. This fact may compromise the conclusions reported in this SM. At this point, we decided not to apply any quality criteria 
to the studies. As recommended by Petersen et al. [36], if we discarded studies of possibly low quality, we could erroneously conclude that the studies are more mature than they are. Besides, important information such as tools used and challenges and difficulties encountered could be overlooked by refusing some studies.

\section{Related Work}

This section presents other secondary studies that relate gamification and SE. As gamification is a new trend in SE, we believe it is important to monitor its evolution. Several secondary studies have been found. Some studies addressed gamification in SE in a general context, and most of the others addressed the use of gamification in some specific context of SE.

Starting with the specific studies, some of them addressed the use of gamification in teamwork. In this context, it is possible to mention the study by Muñoz et al. [13], who performed an informal literature review to understand how gamification influences collaborative work in software development teams. Muñoz et al. found 31 primary studies and, differently from our study, they reported on the use of gamification focused on facilitating teamwork, both in the educational and in the enterprise context. They reported that, in the first case, gamification works by improving the students' skills and knowledge. In the second case, gamification improves the social interaction of the teams. In both cases, gamification attempts to improve the motivation and commitment of team members. An interesting point raised by Muñoz et al. is that most of the gamification tools are web-based. Similarly to one of the analysis we present in our article, Muñoz et al. reported on major difficulties and benefits achieved by the use of gamification. However, the key difference is that they presented such information from the teamwork viewpoint.

In the same line, we refer to Hernández et al.'s studies [18, 17]. Both studies reported on the same literature review, which focused on the use of gamification as a motivating factor in software development teams. In total, Hernández et al. found 31 primary studies. In general, the selected studies addressed gamification as a way to create and support teamwork, with the main objective of inducing the accomplishment of the activities. Different gamification elements were found, and one of the main contributions of the work is the identification of the main factors to consider when choosing the most suitable gamification elements, namely: the environment in which they will be implemented; the way they are applied; and the target audience.

Hernández et al., as well as Muñoz et al. (and unlike this work), took into account studies of gamification in the educational context. In this context, studies on the application of gamification to support teamwork in SE courses were selected. Regarding the application in the software industry, Hernández et al. identified the use of gamification as a way to improve team skills, both individually and at the team level.

In 2018, Machuca-Villegas and Gasca-Hurtado published a Systematic Mapping [19] and a Systematic Literature Review [20]. Both investigated the use of gamification specifically for software project management initiatives. In the Systematic Mapping [19], the authors selected 55 studies published between 2011 and 2017. Similarly to us, Machuca-Villegas and 
Gasca-Hurtado recognized that the gamification area is under development, and that the number of studies has increased over the years. The lack of experimental studies was also noted. However, unlike our study, the authors kept the focus on the project management part, and considered studies in both academic and industrial contexts.

In the Systematic Literature Review [20], for the same period, 49 studies were selected. The achieved results indicate a predominance of studies in project management areas related to integration, resources, and scoping. As other secondary studies, Machuca-Villegas and Gasca-Hurtado found studies in a very preliminary stage. This indicates a need to evolve the software project management area. Both reviews by Machuca-Villegas and Gasca-Hurtado took into account serious games as a manifestation of gamification. Studies with focus on serious games were not selected in our study.

Regarding software process improvement, Gomez-Alvarez et al. [21] performed a Systematic Mapping to investigate the use of gamification in process improvement approaches, identifying and categorizing existing proposals. The low number of selected studies (13, in total) reflects how recent is the use of gamification in that context. Another fact that reinforces this lack of maturity in the use of gamification is the scarcity of experimental studies. As we emphasized along our article, there is a substantial number of studies that lack experimental evaluation.

There are three studies addressing the application of gamification on requirements engineering activities. Two of them are informal reviews [22, 23], whereas the other is a Systematic Literature Review [24]. In one informal review, Unkelos-Shpigel and Hadar [22] analyzed 62 primary studies retrieved with Google Scholar. The study established a relationship between the elements of gamification and their use in improving the performance of the participants, as well as their participation and engagement in the requirements collection process. All of these relationships have been found and are described in more detail in our study. In the other informal review, Mannov [23] provided a compilation of gamification usage presented within the IEEE Requirements Engineering (RE) Conference from 2007 to 2017. Altogether, 8 studies were found. The author identified many serious games that used to assist in requirements engineering. All of these serious games were also found in our study, but were discarded because the focus of our research is on gamification only. Another interesting point discussed by Mannov is that shifting a gamified part to a mobile application increases the access to data and facilitates the involvement of stakeholders.

In addition to the two aforementioned informal reviews, Cursino et al. 24] conducted a Systematic Literature Review on the application of gamification in requirements engineering. As previous secondary studies, a low number of primary studies was found (8 studies, in total). The concentration of the use of game elements on points, badges, and leaderboards calls the author's attention. The major consequence of applying gamification was to increase of stakeholders engagement on requirements engineering activities. Improving the cooperation and communication between teams and stakeholders, or increasing the quality of requirements, are other consequences achieved by applying game elements in the activity.

Other studies were performed by Mäntylä and Smolander [25] and Jesus et al. [26]. In those studies, the authors addressed gamification initiatives in software testing. Mäntylä and Smolander selected 20 studies and showed that gamification has been used for a more 
technical context (such as unit testing) and end-user testing (such as beta-testing and exploratory testing). Jesus et al., on the other hand, selected 15 studies and showed that gamification has been used with the aim of increasing engagement and motivation, and improving skills, but without any clear focus on particular testing technique, level or process phase. Like our study, Mäntylä and Smolander, and Jesus et al., listed several used gamification elements. Among them, the most used was points. Another important detail raised by Mäntylä and Smolander [25] regards the challenges of implementing gamification in the context of software testing.

As discussed in this article, another focus of interest in the studies is the association of gamification with agile processes. In this case, Alhammad and Moreno conducted a Systematic Mapping that retrieved studies from 2011 to 2017 [27]. In total, 6 studies were found. Just like the other secondary studies, Alhammad and Moreno revealed that current research in the field is at the very early stages. There are very few studies and most of them reported on very preliminary results and did not provide empirical evidence of the impact of gamification on the agile process.

In addition to the secondary studies presented above, there is a group of three studies that address the use of gamification more broadly in SE and are a little closer to our study [28, 29, 30]. The first is a Systematic Literature Review by Olgun et al. [28] that encompassed 10 studies published from 2010 to 2017 on the application of gamification in the context of software development. According to the authors, one of the main benefits of gamification in the context of software development is the increase in user motivation, engagement, and collaboration. Moreover, they reported that gamification also helps to increase software quality and performance, and to resolve the obstacles related to human factors. In spite of these observations, one of the main raised points is that the decision for adopting gamification in real projects requires explicit evidence produced through empirical studies.

The second study, which is the closest to ours, is the Systematic Mapping reported by Pedreira et al. [29]. The authors analyzed studies published up to June 2014 with the aim of characterizing the state of the art of gamification in the context of software engineering.

The search string used in this article is based on the Pedreira et al. [29]'s one. For comparison purposes, in Figure 9 we highlight the differences between our string the string used by them. We added keywords - extracted from some other previously known studies — with the aim of enlarging the set of retrieved studies.

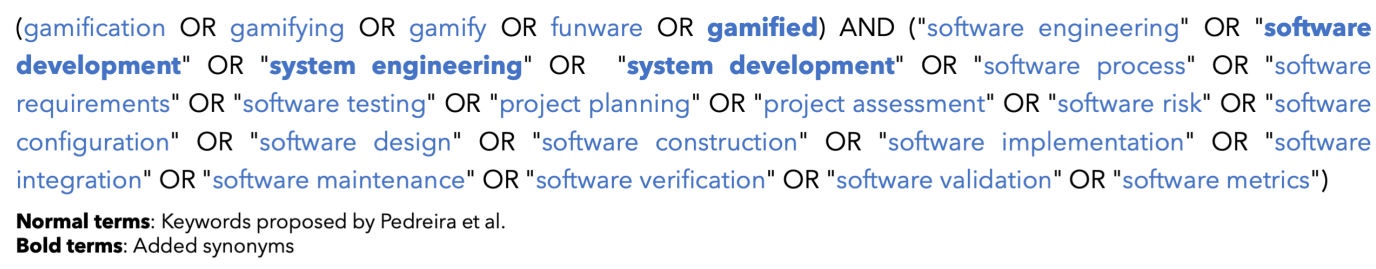

Figure 9: Used search string.

Pedreira et al. [29] analyzed primary studies published up to June 2014; that is, such study is outdated. Moreover, at that time, evidence concerning gamification applied in the SE field was mostly preliminary. As a way to confirm the need for a new secondary study 
on the topic of gamification in SE, we applied to Pedreira et al. [29]' study the framework originally proposed by Garner et al. [44] and evaluated in the context of SE by Mendes et al. [45]. Specifically, Mendes et al. applied the framework in the context of systematic literature reviews; despite this, we understand that the questions are generic enough to be applied also in the context of SMs. The results in our case signaled positively for a new secondary study (details can be checked in Appendix A).

It is important to notice that there are substantial differences between Pedreira et al.'s study and this one. In their study, the authors aimed to identify which software processes are covered by gamification; for this, the ISO/IEC 12207 standard (with two additional process areas) was used. In our study, CMMI 2.0 practice areas were taken into account. Another point of difference between both studies is that only our study has specific research questions regarding the tools and the challenges and difficulties of implementing gamification in software engineering. In total, Pedreira et al. analyzed 29 studies, and this set includes both academic non-academic studies - the latter ones retrieved with the ordinary Google search engine 10 Pedreira et al.'s study set and our study set have only 14 primary studies in common due to two main reasons: we did not use ordinary Google search engine, and we applied more rigorous exclusion criteria. As results, the authors showed how recent the implementation of gamification in SE was until that moment, as well as that most of the studies focused on development activities. They also noticed the use of a few gamification elements (such as points and badges), as well as the lack of empirical evidence of the impact of gamification. We highlight that many other studies in the topic have emerged since Pedreira et al.'s study was published. Ever since, as we report in this study, the diversity of gamification elements and areas where gamification is applied have increased. Nevertheless, there is still little empirical evidence and a lack of reports on how to integrate gamification tools with existing tools in software companies.

The third study closest to ours is a tertiary study by García-Mireles and Morales-Trujillo [30] that aimed to analyze the application of gamification in software engineering. The study retrieved 12 secondary studies published between 2015 and 2018. The majority of studies reported on the usage of points, badges, and leaderboards as game elements in software engineering process, software engineering methods and tools, and software engineering management. From the studies analyzed by García-Mireles and Morales-Trujillo [30], 7 out of 12 are described in this section: [20, 24, 26, 21, 17, 28, 29]. It is worth noting that not all studies recovered by García-Mireles and Morales-Trujillo [30] are described in this section as some of them addressed the application of gamification in an educational context.

For general comparison purposes, all studies described in this section are listed in Table 21. Specifically, the comparison is made between the research questions of this work (see Section 2.1 for more details) with those of the other studies. The symbol $\mathbf{T}$ is used if a research question is fully answered in the related study. If a research question is not fully answered in the related study (e.g. the question is not a research question in the related study, but it somehow commented on throughout the text.) the symbol $\mathbf{O}$ is used. Finally, the symbol $\mathbf{O}$ is used if the research question is not answered in the related study. For

\footnotetext{
${ }^{10}$ https://www.google.com - accessed on 13-September-2020
} 
example, Hernández et al.'s study [17] has a research question about gamification elements that is very similar to our RQ1. Consequently, in Table 21, RQ1 is marked with the symbol. Likewise, our RQ2 is not a research question defined in the study of Hernández et al. [17], but is commented on throughout the text. Thus, RQ2 is marked with the $\mathbf{O}$ symbol. It is also worth noting that most of the related studies are restricted to a specific area of software engineering such as teamworks [17, 18, 13] and project management [19, 20], Therefore, even if a research question is marked with $\mathbf{O}$, it does not bring the same results presented in our study. Note that even in the more general studies [28, 29, 30] (i.e. the last three listed in Table 21) have low coverage of the research questions defined for this study, and analyzed much smaller sets of primary studies.

Many things have changed since the secondary and tertiary studies described in this section have been published. If on the one hand, some information remains the same (e.g. points as the most use gamification element, and the existence of immature and preliminary studies), on the other hand, much new information has emerged from this study. The main new findings of this study, particularly in comparison with to the study of Pedreira et al. [29], are:

- Even with many immature and preliminary studies, 22 selected studies reported controlled experiments in this mapping;

- The number of studies selected in our mapping was substantially higher. In total, we found and analyzed 103 studies against 29 studies analyzed in the prior mapping, what represents 3.5 times more studies. This means that the subject is still being addressed by the researchers. We highlight that 17 studies published in journals were found in this mapping, whereas only 2 were found in the prior mapping [29];

- This mapping is the first that explicitly presents a list of difficulties and challenges of implementing gamification in SE activities in general (that is, not focused on a narrow set of SE activities);

- More studies were found on project management (15 against 5), requirements (22 against 2), and configuration management (3 against 2);

- This mapping revealed the existence of 46 tools to support gamification;

- Some tools are already evolving, including six that are already integrated with the existing company's tools.

\section{Conclusion and Future Work}

The purpose of this paper was reporting on the results of a systematic literature mapping about gamification and its application in the context of software engineering. The scope of interest planned in this study, in order to reach the main goal, involved: the evolution of research on this topic based on the number of publications; the gamification elements that have been adopted, and in which software engineering activities; the benefits that have 
Table 21: Secondary and tertiary studies related to our study.

\begin{tabular}{|c|c|c|c|c|c|c|c|c|c|c|}
\hline Ref & Authors & Title & Year & $\begin{array}{l}\text { \# Analyzed } \\
\text { studies }\end{array}$ & Main focus & RQ1 & RQ2 & RQ2.1 & RQ3 & RQ4 \\
\hline [17] & Hernández et al. & $\begin{array}{l}\text { A systematic literature review } \\
\text { focused on the use of gamifi- } \\
\text { cation in software engineering } \\
\text { teamworks }\end{array}$ & 2017 & 31 & Teamworks & & 0 & O & & $\mathrm{O}$ \\
\hline 18 & Hernández et al. & $\begin{array}{l}\text { Gamification in software engi- } \\
\text { neering teamworks: A system- } \\
\text { atic literature review }\end{array}$ & 2016 & 31 & Teamworks & & 0 & O & $\mathrm{O}$ & O \\
\hline 13 & Muñoz et al. & $\begin{array}{l}\text { State of the use of gamification } \\
\text { elements in software develop- } \\
\text { ment teams }\end{array}$ & 2017 & 31 & Teamworks & & 0 & O & 0 & O \\
\hline 19 & $\begin{array}{l}\text { Machuca-Villegas } \\
\text { and Gasca-Hurtado }\end{array}$ & $\begin{array}{l}\text { Gamification for improving } \\
\text { software project: Systematic } \\
\text { mapping in project manage- } \\
\text { ment }\end{array}$ & 2018 & 55 & $\begin{array}{l}\text { Project Man- } \\
\text { agement }\end{array}$ & O & 0 & O & $\mathrm{O}$ & O \\
\hline 20 & \begin{tabular}{|l} 
Machuca-Villegas \\
and Gasca-Hurtado
\end{tabular} & $\begin{array}{l}\text { Gamification for improving } \\
\text { software project manage- } \\
\text { ment processes: A systematic } \\
\text { literature review }\end{array}$ & 2018 & 49 & $\begin{array}{l}\text { Project Man- } \\
\text { agement }\end{array}$ & ○ & 0 & $\mathrm{O}$ & O & O \\
\hline 21 & Gomez-Alvarez et al. & $\begin{array}{l}\text { Gamification as strategy for } \\
\text { software process improvement: } \\
\text { A systematic mapping }\end{array}$ & 2017 & 13 & $\begin{array}{l}\text { Software pro- } \\
\text { cess improve- } \\
\text { ment }\end{array}$ & 0 & O & O & $\mathrm{O}$ & \\
\hline 22 & $\begin{array}{l}\text { Unkelos-Shpigel and } \\
\text { Hadar }\end{array}$ & $\begin{array}{l}\text { Leveraging Motivational Theo- } \\
\text { ries for Designing Gamification } \\
\text { for } \mathrm{RE}\end{array}$ & 2018 & 62 & $\begin{array}{l}\text { Requirements } \\
\text { Engineering }\end{array}$ & & 0 & $\mathrm{O}$ & $\mathrm{O}$ & O \\
\hline 23 & Mannov & $\begin{array}{l}\text { Freud, Kierkegaard, and gami- } \\
\text { fication in RE }\end{array}$ & 2018 & 8 & $\begin{array}{l}\text { Requirements } \\
\text { Engineering }\end{array}$ & 0 & O & O & 0 & O \\
\hline 24 & Cursino et al. & $\begin{array}{l}\text { Gamification in Requirements } \\
\text { Engineering: A Systematic Re- } \\
\text { view }\end{array}$ & 2018 & 8 & $\begin{array}{l}\text { Requirements } \\
\text { Engineering }\end{array}$ & & - & O & $\mathrm{O}$ & \\
\hline 25 & $\begin{array}{l}\text { Mäntylä } \\
\text { Smolander }\end{array}$ & $\begin{array}{l}\text { Gamification of software test- } \\
\text { ing - An MLR }\end{array}$ & 2016 & 20 & Testing & & O & O & O & \\
\hline 26 & Jesus et al. & $\begin{array}{l}\text { Gamification in software test- } \\
\text { ing: A characterization study }\end{array}$ & 2018 & 15 & Testing & & O & O & 0 & O \\
\hline 27. & Alhammad and & $\begin{array}{l}\text { What is going on in agile gam- } \\
\text { ification? }\end{array}$ & 2018 & 6 & Agile process & & & 0 & & O \\
\hline 28 & Olgun et al. & $\begin{array}{l}\text { A systematic investigation into } \\
\text { the use of game elements in } \\
\text { the context of software busi- } \\
\text { ness landscapes: a systematic } \\
\text { literature review. }\end{array}$ & 2017 & 10 & $\mathrm{ES}$ in general & O & O & $\mathrm{O}$ & 0 & O \\
\hline 29 & Pedreira et al. & $\begin{array}{l}\text { Gamification in software engi- } \\
\text { neering - A systematic map- } \\
\text { ping }\end{array}$ & 2015 & 29 & ES in general & O & 0 & O & $\mathrm{O}$ & 0 \\
\hline 30 & $\begin{array}{l}\text { García-Mireles and } \\
\text { Morales-Trujillo }\end{array}$ & $\begin{array}{l}\text { Gamification in Software Engi- } \\
\text { neering: A Tertiary Study }\end{array}$ & 2019 & 12 & $\mathrm{ES}$ in general & 0 & 0 & O & O & 0 \\
\hline
\end{tabular}


been achieved; the relationship between the activities supported by gamification and the process maturity, having the CMMI 2.0 model as reference; the tools that have been used to support gamification in certain activities; and, finally, the challenges and difficulties of deploying gamification in the software engineering context. The conclusions herein presented build from the analysis of 103 selected studies.

Based on those points of view, we noticed an annual increase in the number of publications regarding the use of gamification in software engineering activities. This indicates that this area is still new, since the first publications date from 2011. More importantly, we noticed that there is not strong empirical evidence, thus suggesting many gaps for investigations. These gaps were discussed in Section 4 .

Despite the existence of several gamification elements, we found out that the most used ones in the investigated context are points and leaderboards; both are present in the activities of Project Management, Requirements, Development, Testing, and Support Processes. Some major benefits achieved with the use of gamification were: engagement and motivation to perform the activities; encouragement for code review tasks; engagement of stakeholders during requirements elicitation; and improvement in agile processes, in which the more dynamic profile seems to make the use of gamification more propitious.

Regarding the software process maturity, the activities supported by gamification were mapped to the CMMI 2.0 Practice Areas. As a result, we identified gamification initiatives related mainly to: Technical solution (TS); Product integration (PI); Verification and validation (VV); and Requirements development and management (RDM). With respect to the use of gamified tools, this is an important matter in the gamification adoption, and 57 out of 103 selected studies explicitly cited this type of support.

Despite the fact that gamification is a recent topic of interest, several studies already pointed out difficulties and challenges for its implementation. The main challenges reported by the studies are set a fair assignment of points or reward and, at the same time, enjoyable to the players; conducting empirical studies; and the difficulty for implementing a tool or a gamified environment. Other 15 issues were reported as difficulties faced while introducing gamification in the software development process.

As future work, we intend to investigate more deeply how gamification may be used to improve software processes, and what is the relationship between gamification and agile processes. We will also investigate what are the reasons for the lack of studies that address gamification applied to some CMMI Practice Areas, and how to solve the challenges and difficulties found in this review.

\section{Acknowledgements}

This study was financed in part by the Coordenação de Aperfeiçoamento de Pessoal de Nível Superior - Brasil (CAPES) - Finance Code 001, and Conselho Nacional de Desenvolvimento Científico e Tecnológico - Brasil (CNPq) - grants 306310/2016-3 and 167513/2017-6. 


\section{References}

[1] The Standish Group, CHAOS Report: Decision Latency Theory: It Is All About the Interval, The Standish Group, 2 edition, 2018.

[2] D. J. Dubois, G. Tamburrelli, Understanding gamification mechanisms for software development, in: Proceedings of the 9th Joint Meeting on Foundations of Software Engineering, ACM Press, 2013, pp. 659-662.

[3] S. Deterding, D. Dixon, R. Khaled, L. Nacke, From Game Design Elements to Gamefulness, in: Proceedings of the 15th International Academic MindTrek Conference: Envisioning Future Media Environments, ACM Press, 2011, pp. 9-15.

[4] F. García, O. Pedreira, M. Piattini, A. Cerdeira-Pena, M. Penabad, A framework for gamification in software engineering, Journal of Systems and Software 132 (2017) 21-40.

[5] K. M. Kapp, The Gamification of Learning and Instruction: Game-based Methods and Strategies for Training and Education, Pfeiffer \& Company, 1st edition, 2012.

[6] B. Monterrat, E. Lavoué, S. George, Toward an adaptive gamification system for learning environments, in: Proceedings of the 6th International Conference on Computer Supported Education, Springer, 2015, pp. $115-129$.

[7] C. Latulipe, N. B. Long, C. E. Seminario, Structuring flipped classes with lightweight teams and gamification, in: Proceedings of the 46th Technical Symposium on Computer Science Education, ACM Press, 2015, pp. 392-397.

[8] G. Barata, S. Gama, J. A. P. Jorge, D. J. V. Gonçalves, Relating Gaming Habits with Student Performance in a Gamified Learning Experience, in: Proceedings of the 1st annual symposium on Computer-human interaction in play, ACM Press, 2014, pp. 17-25.

[9] C. Muntean, Raising engagement in e-learning through gamification, in: Proceedings of the 6th International Conference on Virtual Learning, Bucharest University Press, 2011, pp. 323-329.

[10] S. Deterding, R. Khaled, L. Nacke, D. Dixon, Gamification: Toward a Definition, in: Proceedings of the 29th Conference on Human Factors in Computing Systems - Gamification workshop, ACM Press, 2011, pp. 12-15.

[11] J. Hamari, J. Koivisto, H. Sarsa, Does gamification work? - a literature review of empirical studies on gamification, in: Proceedings of the 47th Hawaii International Conference on System Sciences, IEEE, 2014, pp. 3025-3034.

[12] S. Beecham, N. Baddoo, T. Hall, H. Robinson, H. Sharp, Motivation in Software Engineering: A Systematic Literature Review, Information and Software Technology 50 (2008) 860-878.

[13] M. Muñoz, L. Hernández, J. Mejia, G. P. Gasca-Hurtado, M. C. Gómez-Alvarez, State of the use of gamification elements in software development teams, in: Proceedings of the 24th European Conference on Software Process Improvement, Springer, 2017, pp. 249-258.

[14] L. Singer, K. Schneider, It was a bit of a race: Gamification of version control, in: Proceedings of the 2nd International Workshop on Games and Software Engineering, IEEE, 2012, pp. 5-8.

[15] G. Fraser, Gamification of software testing, in: Proceedings of the 12th International Workshop on Automation of Software Testing, IEEE, 2017, pp. 2-7.

[16] A. Dorling, F. McCaffery, The gamification of SPICE, in: Proceedings of the 12th International Conference on Software Process Improvement and Capability, Springer, 2012, pp. 295-301.

[17] L. Hernández, M. Muñoz, J. Mejía, A. Peña, N. Rangel, C. Torres, Una revisión sistemática de la literatura enfocada en el uso de gamificación en equipos de trabajo en la ingeniería de software, Revista Ibérica de Sistemas e Tecnologias de Informação (2017) 33-50.

[18] L. Hernández, M. Muñoz, J. Mejía, A. Peña, Gamification in software engineering teamworks: A systematic literature review, in: Proceedings of the 5th International Conference on Software Proceess Improvement, IEEE, 2016, pp. 1-8.

[19] L. Machuca-Villegas, G. P. Gasca-Hurtado, Gamification for improving software project: Systematic mapping in project management, in: Proceedings of the 13th Iberian Conference on Information Systems and Technologies, IEEE, 2018, pp. 1-6.

[20] L. Machuca-Villegas, G. P. Gasca-Hurtado, Gamification for improving software project management 
processes: A systematic literature review, in: Proceedings of the 7th International Conference on Software Process Improvement, Springer International Publishing, 2018, pp. 41-54.

[21] M. C. Gomez-Alvarez, G. P. Gasca-Hurtado, J. A. Hincapie, Gamification as strategy for software process improvement: A systematic mapping, in: Proceedings of the 12th Iberian Conference on Information Systems and Technologies, IEEE, 2017, pp. 1-7.

[22] N. Unkelos-Shpigel, I. Hadar, Leveraging motivational theories for designing gamification for RE, in: Proceedings of the 11th International Workshop on Cooperative and Human Aspects of Software Engineering, ACM Press, 2018, pp. 69-72.

[23] N. Mannov, Freud, kierkegaard, and gamification in RE, in: Proceedings of the 1st International Workshop on Learning from other Disciplines for Requirements Engineering, IEEE, 2018, pp. 29-32.

[24] R. Cursino, D. Ferreira, M. Lencastre, R. Fagundes, J. Pimentel, Gamification in requirements engineering: A systematic review, in: Proceedings of the 11th International Conference on the Quality of Information and Communications Technology, IEEE, 2018, pp. 119-125.

[25] M. V. Mäntylä, K. Smolander, Gamification of software testing - an MLR, in: Proceedings of the 17th International Conference on Product-Focused Software Process Improvement, Springer, 2016, pp. 611-614.

[26] G. M. Jesus, F. C. Ferrari, D. P. Porto, S. C. P. F. Fabbri, Gamification in Software Testing: A Characterization Study, in: Proceedings of the 3rd Annual ACM Brazilian Symposium on Systematic and Automated Software Testing, ACM Press, 2018, pp. 39-48.

[27] M. M. Alhammad, A. M. Moreno, What is going on in agile gamification?, in: Proceedings of the 19th International Conference on Agile Software Development Companion, ACM Press, 2018, pp. 1-4.

[28] S. Olgun, M. Yilmaz, P. M. Clarke, R. V. O'Connor, A systematic investigation into the use of game elements in the context of software business landscapes: A systematic literature review, in: Proceedings of the 17th International Conference Process Improvement and Capability Determination, Springer International Publishing, 2017, pp. 384-398.

[29] O. Pedreira, F. García, N. Brisaboa, M. Piattini, Gamification in software engineering - a systematic mapping, Information and Software Technology 57 (2015) 157-168.

[30] G. A. García-Mireles, M. E. Morales-Trujillo, Gamification in software engineering: A tertiary study, in: Proceedings of the 8th International Conference on Software Process Improvement, Springer International Publishing, 2019, pp. 116-128.

[31] CMMI Institute , CMMI Adoption Trends - 2018 Year End Update, 2018. Avaliable at: https://cmmiinstitute.com/resource-files/public/cmmi-adoption-trends-2018-year-end-update. Accessed on 23-April-2020.

[32] CMMI Institute, Do ISO Standards And CMMI Work Together?, 2009. Avaliable at: https://cmmiinstitute.zendesk.com/hc/en-us/articles/115004587567-Do-ISO-standards-and-CMMIwork-together-. Accessed on 23-April-2020.

[33] N. Ehsan, A. Perwaiz, J. Arif, E. Mirza, A. Ishaque, CMMI / SPICE based process improvement, in: Proceedings of the 5th International Conference on Management of Innovation \& Technology, IEEE, 2010, pp. 859-862.

[34] CMMI Institute, A Guide to Scrum and CMMIR: Improving Agile Performance with CMMI, 2016. Avaliable at: https://cmmiinstitute.com/resource-files/public/marketing/document/a-guide-to-scrumand-cmmiß-improving-agile-perfor. Accessed on 23-April-2020.

[35] K. Petersen, R. Feldt, S. Mujtaba, M. Mattsson, Systematic mapping studies in software engineering, in: Proceedings of the 12th international conference on Evaluation and Assessment in Software Engineering, BCS Learning \& Development Ltd., 2008, pp. 68-77.

[36] K. Petersen, S. Vakkalanka, L. Kuzniarz, Guidelines for conducting systematic mapping studies in software engineering: An update, Information and Software Technology 64 (2015) 1-18.

[37] B. Kitchenham, S. Charters, Guidelines for performing Systematic Literature Reviews in Software Engineering, Technical Report Technical Report EBSE 2007-001, School of Computer Science and Mathematics, Keele University, 2007.

[38] C. Wohlin, Guidelines for snowballing in systematic literature studies and a replication in software 
engineering, in: Proceedings of the 18th International Conference on Evaluation and Assessment in Software Engineering, ACM Press, 2014, pp. 321-330.

[39] S. Fabbri, C. Silva, E. Hernandes, F. Octaviano, A. D. Thommazo, A. Belgamo, Improvements in the StArt tool to better support the systematic review process, in: Proceedings of the 20th International Conference on Evaluation and Assessment in Software Engineering, ACM Press, 2016, pp. 1-5.

[40] R. Wieringa, N. Maiden, N. Mead, C. Rolland, Requirements engineering paper classification and evaluation criteria: a proposal and a discussion, Requirements Engineering 11 (2005) 102-107.

[41] K. Werbach, D. Hunter, For the win: How game thinking can revolutionize your business, Wharton Digital Press, 2012.

[42] CMMI Institute, Cmmi development v2.0 quick reference guide, 2018.

[43] X. Zhou, Y. Jin, H. Zhang, S. Li, X. Huang, A map of threats to validity of systematic literature reviews in software engineering, in: Proceedings of the 23rd Asia-Pacific Software Engineering Conference, IEEE, 2016, pp. 153-160.

[44] P. Garner, S. Hopewell, J. Chandler, H. MacLehose, H. J. Schünemann, E. A. Akl, J. Beyene, S. Chang, R. Churchill, K. Dearness, G. Guyatt, C. Lefebvre, B. Liles, R. Marshall, L. M. García, C. Mavergames, M. Nasser, A. Qaseem, M. Sampson, K. Soares-Weiser, Y. Takwoingi, L. Thabane, M. Trivella, P. Tugwell, E. Welsh, E. C. Wilson, When and how to update systematic reviews: consensus and checklist, BMJ (2016) 1-10.

[45] E. Mendes, C. Wohlin, K. Felizardo, M. Kalinowski, When to update systematic literature reviews in software engineering, Journal of Systems and Software 167 (2020) 1-24.

\section{Appendix A. Is a new secondary study needed?}

In the application of the framework [44, 45], we used as a baseline the study of Pedreira et al. [29] - as it is the closest study to what we wanted - and executed the proposed checklist. The checklist and responses are shown in the table below. The table reveals that the responses for the three questions in step 1 are YES, which enables us to proceed to the next step. At least one YES response in step 2 enables us to move on to the last step. In the third step, at least one YES response gives us confirmation to proceed with the study update (or, as in our case, for a new study).

\begin{tabular}{lc}
\hline Framework Step & Response \\
\hline Step 1.a - Does the published SLR still address a current question? & YES \\
Step 1.b - Has the SLR had good access or use? & YES \\
Step 1.c - Has the SLR used valid methods and was well-conducted? & YES \\
Step 2.a - Are there any new relevant methods? & YES \\
Step 2.b - Are there any new studies, or new information? & YES \\
Step 3.a - Will the adoption of new methods change the findings, conclusions or credibility? & YES \\
Step 3.b - Will the inclusion of new studies/information/data change findings, conclusions or credibility? & YES \\
\hline
\end{tabular}

\section{Appendix B. List of primary studies}

\begin{tabular}{lllcl}
\hline Id & Author & Title & Year & Journal/Event \\
\hline$[\mathrm{S} 1]$ & $\begin{array}{l}\text { C. R. Prause and J. Nonnen } \\
\text { and M. Vinkovits }\end{array}$ & $\begin{array}{l}\text { A Field Experiment on Gamification of } \\
\text { Code Quality in Agile Development }\end{array}$ & 2012 & $\begin{array}{l}\text { Workshop Psychology of Pro- } \\
\text { gramming Interest Group }\end{array}$ \\
[S2] & $\begin{array}{l}\text { F. García and O. Pedreira and } \\
\text { M. Piattini and A. Cerdeira- } \\
\text { Pena and M. Penabad }\end{array}$ & $\begin{array}{l}\text { A framework for gamification in software } \\
\text { engineering }\end{array}$ & 2017 & $\begin{array}{l}\text { Journal of Systems and Soft- } \\
\text { ware }\end{array}$
\end{tabular}


[S3] L. Elezi and S. Sali and S. Demeyer and A. Murgia and $\mathrm{J}$. Pèrez

[S4] V. S. Sharma and V. Kaulgud and P. Duraisamy

[S5] G.P. Gasca-Hurtado and M.C. Gómez-Alvarez and M. Muñoz and A. Peña

[S6] S. Arai and K. Sakamoto and H. Washizaki and Y. Fukazawa

[S7] M. Muñoz and L. Hernández and J. Mejia and A. Peña and N. Rangel and C. Torres and G. Sauberer

[S8] T. Barik and E. Murphy-Hill and T. Zimmermann

[S9] F. Steffens and S. Marczak and F. F. Filho and C. Treude and C. R. B. de Souza

[S10] M. Yilmaz and R. Oconnor

[S11] I. Chow and L. Huang

[S12] S.A. Scherr and F. Elberzhager and K. Holl

[S13] V. S. Sharma and V. Kaulgud

[S14] L. Piras

[S15] J.I. Galván-Tejada and J.G. Arceo-Olague and J.M. Celaya-Padilla and R. SolisRobles

[S16] M. Johansson and E. Ivarsson

[S17] A. McClean

[S18] M. Tsunoda and H. Yumoto

[S19] S. K. Sripada and Y. R. Reddy and S. Khandelwal

[S20] N. U. Shpigel

[S21] M. Z. H. Kolpondinos and M. Glinz

[S22] P.S. Neto and D.B. Medeiros and I. Ibiapina and O.C. Da Costa Castro

[S23] A. Uskarci and O. Demirörs

[S24] T. D. LaToza and W. Ben Towne and A. van der Hoek and J. D. Herbsleb

[S25] R. Snijders and F. Dalpiaz and M. Hosseini and A. Shahri and R. Ali

[S26] E. Herranz and R. ColomoPalacios and A. Al-Barakati

[S27] L. Piras and D. Dellagiacoma and A. Perini and A. Susi and P. Giorgini and J. Mylopoulos
A game of refactoring: Studying the Impact of Gamification in Software Refactoring

A gamification approach for distributed agile delivery

A Gamified Proposal for Software Risk Analysis in Agile Methodologies

A gamified tool for motivating developers to remove warnings of bug pattern tools A model to integrate highly effective teams for software development

A perspective on blending programming environments and games: Beyond points, badges, and leaderboards

A preliminary evaluation of a gamification framework to jump start collaboration behavior change

A scrumban integrated gamification approach to guide software process improvement: A Turkish case study A software gamification model for crosscultural software development teams

Acceptance testing of mobile applications: Automated emotion tracking for large user groups

Agile workbench: Tying people, process, and tools in distributed agile delivery

Agon: a Gamification-Based Framework for Acceptance Requirements

An approach to make software testing for users with down syndrome a little more pleasant

An Experiment on the Effectiveness of Unit Testing when Introducing Gamification

An Exploration of the Use of Gamification in Agile Software Development Applying Gamification and Posing to Software Development

Architecting an extensible framework for gamifying software engineering concepts Be ahead of the game: Gamification for inclusive $\mathrm{RE}$

Behind Points and Levels - The Influence of Gamification Algorithms on Requirements Prioritization

Case study of the introduction of game design techniques in software development

Causes of Continuity and Participation Problems in Process Improvement with Staged Maturity Models

Crowd development

Crowd-centric Requirements Engineering

Deploying a gamification framework for software process improvement: Preliminary results

Design Thinking and Acceptance Requirements for Designing Gamified Software
2016 Scientific Workshop Proceedings of XP2016

2016 International Workshop on Games and Software Engineering

2019 European Conference on Software Process Improvement

2014 Workshop on Empirical Software Engineering in Practice

2017 European Conference on Software Process Improvement

2016 Symposium on Visual Languages and Human-Centric Computing

2017 International Workshop on Cooperative and Human Aspects of Software Engineering

2016 Tehnicki vjesnik - Technical Gazette

2017 International Conference on Management Engineering, Software Engineering and Service Sciences

2018 International Conference on Mobile Software Engineering and Systems

2016 International Conference on Global Software Engineering

2018 Università degli Studi di Trento

2018 International Conference on Human-Computer Interaction

2014 Chalmers University of Technology

2015 Technological University Dublin

2018 Asia-Pacific Software Engineering Conference

2016 India Software Engineering Conference

2018 Workshop on Facilitating Inclusive Requirements Engineering

2017 International Requirements Engineering Conference

2019 IET Software

2015 International Conference on Software Process Improvement and Capability Determination

2013 International Workshop on Cooperative and Human Aspects of Software Engineering

2014 International Conference on Utility and Cloud Computing

2017 European Conference on Software Process Improvement

2019 International Conference on Research Challenges in Information Science 
[S28] W. Fracz and J. Dajda

[S29] F. Kifetew and D. Munante and A. Perini and A. Susi and A. Siena and P. Busetta

[S30] W. Sisomboon and N. Phakdee and N. Denwattana

[S31] P. Lombriser

[S32] F. Dalpiaz and R. Snijders and S. Brinkkemper and M. Hosseini and A. Shahri and R. Ali

[S33] M. Muñoz and J. Mejia and A. Peña and N. Rangel

[S34] Ç. Usfekes and M. Yilmaz and E. Tuzun and P. M. Clarke and R. V. O'Connor

[S35] W. Snipes and A. R. Nair and E. Murphy-Hill

[S36] A. Perini and N. Seyff and M. Stade and A. Susi

[S37] M. Foucault and X. Blanc and J.-R. Falleri and M.-A. Storey

[S38] R. Minelli and A. Mocci and M. Lanza

[S39] M. Ruiz and M. Trinidad and A. Calderón

[S40] E. Herranz and R. C. Palacios and A. A. Seco and M. Yilmaz

[S41] D. Silva and A. Coelho and C. Duarte and P. C. Henriques

[S42] C. R. Prause and M. Jarke

[S43] E. Herranz and J. G. Guzmán and A. de Amescua-Seco and X. Larrucea

[S44] V. Platonova and S. Berzisa

[S45] M. Češka

[S46] D. Ašeriškis and R. Damaševičius

[S47] L. Piras and E. Paja and P. Giorgini and J. Mylopoulos and R. Cuel and D. Ponte

[S48] I. M. Pereira and V. J.P. Amorim and M. A. Cota and G. C. Gonçalves

[S49] M. Foucault and X. Blanc and M.-A. Storey and J.-R. Falleri and C. Teyton

[S50] M. Almaliki and N. Jiang and R. Ali and F. Dalpiaz

[S51] P. Lombriser and F. Dalpiaz and G. Lucassen and S. Brinkkemper

[S52] S. Hermanto and E.R. Kaburuan and N. Legowo

[S53] F. M. Kifetew and D. Munante and A. Perini and A. Susi and A. Siena and P. Busetta and D. Valerio
Developers' game: A preliminary study concerning a tool for automated developers assessment

DMGame: A Gamified Collaborative Requirements Prioritisation Tool

Engaging and Motivating Developers by Adopting Scrum Utilizing Gamification

Engaging Stakeholders in Scenario-Based Requirements Engineering with Gamification

Engaging the crowd of stakeholders in requirements engineering via gamification

Establishing Effective Software Development Teams: An Exploratory Model

Examining reward mechanisms for effective usage of application lifecycle management tools

Experiences gamifying developer adoption of practices and tools

Exploring RE knowledge for gamification: Can RE achieve a high score?

Fostering good coding practices through individual feedback and gamification: an industrial case study

Free Hugs - Praising Developers for Their Actions

Gamification and functional prototyping to support motivation towards software process improvement

Gamification as a disruptive factor in software process improvement initiatives Gamification at scraim

Gamification for enforcing coding conventions

Gamification for software process improvement: A practical approach

Gamification framework for software development project processes

Gamification in the SCRUM Software Development Framework

Gamification of a project management system

Gamification solutions for software acceptance: A comparative study of Requirements Engineering and Organizational Behavior techniques

Gamification Use in Agile Project Management: An Experience Report

Gamification: a Game Changer for Managing Technical Debt? A Design Study

Gamified culture-aware feedback acquisition

Gamified Requirements Engineering: Model and Experimentation

Gamified SCRUM Design in Software Development Projects

Gamifying Collaborative Prioritization: Does Pointsification Work?
2018 International Conference on Software Maintenance and Evolution

2017 International Requirements Engineering Conference

2019 International Conference on Information Technology

2015 Utrecht University

2016 Gamification

2016 European Conference on Software Process Improvement

2017 European Conference on Software Process Improvement

2014 International Conference on Software Engineering

2018 International Workshop on Affective Computing for Requirements Engineering

2019 Empirical Software Engineering

2015 International Conference on Software Engineering

2016 International Conference on Product-Focused Software Process Improvement

2014 Journal of Universal Computer Science

2016 International Conference on Serious Games, Interaction, and Simulation

2015 Joint Meeting on Foundations of Software Engineering

2019 IET Software

2019 International Scientific Practical Conference

2015 Masaryk University

2014 International Conference on Advances in Computer-Human Interactions

2017 International Conference on Research Challenges in Information Science

2017 Brazilian Workshop on Agile Methods

2018 arXiv

2014 International Conference on Utility and Cloud Computing

2016 International Working Conference on Requirements Engineering: Foundation for Software Quality

2018 International Conference on Orange Technologies

2017 International Requirements Engineering Conference 
[S54] C. Ribeiro and C. Farinha and J. Pereira and M. M. Silva

[S55] M.E.A. Tebib

[S56] N. Unkelos-Shpigel. and I. Hadar

[S57] R. Marques and G. Costa and M. M. Silva and P. Goncalves

[S58] N. Unkelos-Shpigel and I. Hadar

[S59] L.N.Q. Do and E. Bodden

[S60] E. Herranz and R. ColomoPalacios and A. A. Seco

[S61] M. Z. Kolpondinos and M. Glinz

[S62] M. Tsunoda and T. Hayashi and S. Sasaki and K. Yoshigami and H. Uwano and K. Matsumoto

[S63] K. Yoshigami and T. Hayashi and M. Tsunoda and H. Uwano and S. Sasaki and K. Matsumoto

[S64] A. Poth and M. Kottke

[S65] T. D. Sasso and A. Mocci and M. Lanza and E. Mastrodicasa

[S66] S. Khandelwal and S. K. Sripada and Y. R. Reddy

[S67] S. Maro and E. Sundklev and C.-O. Persson and G. Liebel and J.-P. Steghöfer

[S68] D. Porto and F. Ferrari and S. Fabbri

[S69] R. Marques and G. Costa and M.M. Da Silva and D. Gonçalves and P. Gonçalves

[S70] D. Arnarsson and Í. Jóhannesson

[S71] G. Ivan and P. Carla and C.M.J. Antonio

[S72] N. Unkelos-Shpigel and I. Hadar

[S73] E. Herranz and R. ColomoPalacios

[S74] L. Singer and K. Schneider

[S75] J. Fernandes and D. Duarte and $\mathrm{C}$. Ribeiro and C. Farinha and J. M. Pereira and M. M. Silva

[S76] N. Unkelos-Shpigel and I. Hadar

[S77] E. S. Mastrodicasa
Gamifying requirement elicitation: Practical implications and outcomes in improving stakeholders collaboration Gamifying requirements engineering for better practice

Gamifying software development environments using cognitive principles

Gamifying software development scrum projects

Gamifying software engineering tasks based on cognitive principles: The case of code review

Gamifying static analysis

Gamiware: A gamification platform for software process improvement

GARUSO: a gamification approach for involving stakeholders outside organizational reach in requirements engineering How do gamification rules and personal preferences affect coding?

How does time conscious rule of gamification affect coding and review?

How to Assure Agile Method and Process Alignment in an Organization?

How to gamify software engineering

Impact of Gamification on Code Review Process: An Experimental Study

Impact of Gamification on Trace Link Vetting: A Controlled Experiment

Improving project manager decision with gamification

Improving scrum adoption with gamification

Improving Unit Testing Practices With the Use of Gamification

Introducing gamification to increase staff involvement and motivation when conducting SPI initiatives in small-sized software enterprises

Inviting everyone to play: Gamifying collaborative requirements engineering

Is Gamification a Way to a Softer Software Process Improvement? A Preliminary Study of Success Factors

It was a bit of a race: Gamification of version control

IThink: A game-based approach towards improving collaboration and participation in requirement elicitation

Let's make it fun: Gamifying and formalizing Code review

Ludus opus proficit - A gamification framework for software engineering
2014 Entertainment Computing

\section{CEUR Workshop}

2015 International Conference on Advanced Information Systems Engineering

2017 International Conference on Virtual Worlds and Games for Serious Applications

2015 International Workshop on Cooperative and Human Aspects of Software Engineering

2018 European Software Engineering Conference and Symposium on the Foundations of Software Engineering

2015 European Conference on Software Process Improvement

2019 Requirements Engineering

2018 International Workshop on Empirical Software Engineering in Practice

2019 IEICE Transactions on Information and Systems

2018 European Conference on Software Process Improvement

2017 International Conference on Software Analysis, Evolution and Reengineering

2017 Innovations in Software Engineering Conference

2019 International Working Conference on Requirements Engineering

2019 Brazilian Symposium on Software Quality

2018 Americas Conference on Information Systems

2018 Chalmers University of Technology

2019 IET Software

2015 International Workshop on Empirical Requirements Engineering

2018 European Conference on Software Process Improvement

2012 International Workshop on Games and Software Engineering

2012 International Conference on Games and Virtual Worlds for Serious Applications

2016 International Conference on Evaluation of Novel Software Approaches to Software Engineering

2014 Università della Svizzera Italiana 
[S78] R. M. Parizi

[S79] R. Sukale and M. Pfaff

[S80] N. K. Nagwani and S. Verma

[S81] R. Snijders and F. Dalpiaz and S. Brinkkemper and M. Hosseini and R. Ali and A. Ozum

[S82] A. Alexandrova and L. Rapanotti

[S83] J. P. Souza and A. R. Zavan and D. E. Flôr

[S84] J. Kohl

[S85] S. Marczak and F. F. Filho and L. Singer and C. Treude and F. Steffens and D. Redmiles and B. Al-Ani

[S86] O. Liechti and J. Pasquier and R. Reis

[S87] M. Z. H. Kolpondinos and M. Glinz

[S88] B. Mayer and R. Weinreich

[S89] A. Dorling and F. McCaffery

[S90] P. Busetta and F. M. Kifetew and D. Munante and A. Perini and A. Siena and A. Susi

[S91] G. P. G. Hurtado and M. C. Gómez-Alvarez and M. Muñoz and J. Mejia

[S92] E. Herranz and R. C. Palacios and A. A. Seco and M. Sánchez-Gordón

[S93] E. Herranz and R. C. Palacios and A. A. Seco

[S94] R. M. Parizi and A. Kasem and A. Abdullah

[S95] R. Lotufo and L. Passos and K. Czarnecki

[S96] W. Snipes and V. Augustine and A. R. Nair and E. MurphyHill

[S97] E. C. Prakash and M. Rao

[S98] E. B. Passos and D. B Medeiros and P. A. S. Neto and E. W. G. Clua

[S99] D. J. Dubois and G. Tamburrelli

[S100] F. Steffens and S. Marczak and F. F. Filho and C. Treude and L. Singer and D. Redmiles and B. Al-Ani

[S101] D. Redmiles and B. Al-Ani

[S102] A. A. Melo and M. Hinz and G. Scheibel and C. D. M. Berkenbrock and I. Gasparini and F. Baldo
On the gamification of human-centric traceability tasks in software testing and coding

QuoDocs: Improving Developer Engagement in Software Documentation Through Gamification

Rank-Me: A Java Tool for Ranking Team Members in Software Bug Repositories

REfine: A gamified platform for participatory requirements engineering

Requirements analysis gamification in legacy system replacement projects

Scrum hero: Gamifying the scrum framework

Software Testing Is a Game

Studying Gamification as a Collaboration Motivator for Virtual Software Teams: Social Issues, Cultural Issues, and Research Methods

Supporting agile teams with a test analytics platform: A case study

Tailoring gamification to requirements elicitation: A stakeholder-centric motivation concept

The effect of gamification on software architecture knowledge management: A student experiment and focus group study

The gamification of SPICE

Tool-Supported Collaborative Requirements Prioritisation

Toward an assessment framework for gamified environments

Towards a gamification framework for software process improvement initiatives: Construction and validation

Towards a New Approach to Supporting Top Managers in SPI Organizational Change Management

Towards gamification in software traceability: Between test and code artifacts Towards Improving Bug Tracking Systems with Game Mechanisms

Towards recognizing and rewarding efficient developer work patterns

Transforming learning and it management through gamification

Turning real-world software development into a game

Understanding gamification mechanisms for software development

Using gamification as a collaboration motivator for software development teams: A preliminary framework

Using Gamification to Increase Scrum Adoption

Version control system gamification: A proposal to encourage the engagement of developers to collaborate in software projects
2016 International Conference on Software Engineering Research, Management and Applications

2014 International Conference on Computer Human Interaction

2012 Journal of Software Engineering and Applications

2015 International Workshop on Crowd-Based Requirements Engineering

2019 Requirements Engineering

2017 Brazilian Workshop on Agile Methods

2013 Better Software

2015 Conference on ComputerSupported Collaborative Work and Social Computing

2017 International Workshop on Automation of Software Testing

2017 International Workshop on Cooperative and Human Aspects of Software Engineering

2019 Symposium on Applied Computing

2012 International Conference on Software Process Improvement and Capability Determination

2017 Annual Computer Software and Applications Conference

2017 European Conference on Software Process Improvement

2016 Journal of Universal Computer Science

2013 Conference on ENTERprise Information Systems

2015 International Joint Conference on Software Technologies

2012 Working Conference on Mining Software Repositories

2013 International Conference on Software Engineering

2015 Springer International Publishing

2011 Brazilian Symposium on Games and Digital Entertainment

2013 Joint Meeting on Foundations of Software Engineering

2015 Brazilian Symposium on Collaborative Systems

2015 Brazilian Symposium in Collaborative Systems

2014 International Conference on Social Computing and Social Media 
[S103] D. B. Medeiros and P. A. S. Working and Playing with Scrum Neto and E. B. Passos and W. S. Araújo
2015 International Journal of Software Engineering and Knowledge Engineering 